\title{
EFECTO INCUMBENTE EN ELECCIONES MUNICIPALES: UN ANALISIS DE REGRESION DISCONTINUA PARA GUATEMALA
}

INCUMBENCY EFFECTS IN GUATEMALAN MUNICIPAL ELECTIONS: A REGRESSION DISCONTINUITY DESIGN

\section{IVAN MORALES CARRERA* \\ Independiente}

\begin{abstract}
This thesis has two main objectives: (i) to analyze empirically, using data from municipal elections in Guatemala for the period 1999-2011, the effect of incumbency on the probability of being reelected and (ii) to explore the possible cause of the effects obtained from the estimations. To do this, a regression discontinuity estimation strategy is implemented exploiting the inherent discontinuity in the system of simple majority voting. Paradoxically, the findings show that far from being an advantage, incumbency seems to be an electoral disadvantage. The result extends to political parties. In the second part, the results are mixed, but suggest that elections seem to play an accountability role, but also are an important mechanism to discover the type (or quality) of politicians. This work is an important contribution to the limited literature on the dynamics of local elections in Guatemala and opens the door to future research issues.
\end{abstract}

Keywords: Political economics, regression discontinuity, municipal elections, Guatemala.

JEL Classification: $C 14, C 21, D 72, O 54$.

* E-mail: ijmorales@uc.cl. Agradezco el apoyo de los miembros del EH ClioLab en el Instituto de Economía de la PUC, en especial los valiosos comentarios de Gert Wagner, José Díaz y Jeanne Lafortune. También agradezco la valiosa retroalimentación recibida por Carlos Mendoza y Fernando Villamizar. Cualquier error u omisión contenida en el trabajo es de mi exclusiva responsabilidad. 


\section{Resumen}

El presente trabajo tiene dos objetivos principales: (i) analizar empíricamente, con datos de elecciones municipales en Guatemala para el período 1999 2011, el efecto de la incumbencia sobre la probabilidad de los candidatos de ser reelegidos y (ii) explorar la posible causa de los efectos encontrados. Para ello se implementa una estrategia de estimación de regresión discontinua que explota esto mismo inherente al sistema de votación por mayoría simple. Paradójicamente los resultados encontrados demuestran que lejos de ser una ventaja, la incumbencia parece ser una desventaja electoral. El resultado encontrado se extiende a los partidos políticos. En la segunda parte, los resultados encontrados son mixtos, sin embargo apuntan a que las elecciones parecen cumplir un rol de rendición de cuentas, pero a la vez también juegan un importante rol para descubrir el tipo (o calidad) de los políticos. Este trabajo constituye un importante aporte a la escasa literatura existente sobre la dinámica de las elecciones locales en Guatemala y abre la puerta a la investigación de futuros temas relacionados.

Palabras clave: Economía política, regresión discontinua, elecciones municipales, Guatemala.

Clasificación JEL: C14, C21, D72, $O 54$.

\section{INTRODUCCION}

En la tradición de Downs (1957) y la escuela de public choice, los gobiernos democráticos se caracterizan por la existencia de elecciones periódicas en las que dos o más partidos políticos compiten por el voto popular para lograr que sus candidatos accedan a cargos públicos.

Las elecciones son un elemento central de la democracia y, como demuestra Barro (1973), también constituyen un importante mecanismo de rendición de cuentas o accountability por parte de los políticos en el poder hacia sus electores.

Una dimensión importante de las elecciones ocurre cuando la trayectoria previa del individuo no constituye impedimento para postular nuevamente a un cargo ${ }^{1}$, ello puede dar pie a la existencia de una competencia electoral en condiciones desiguales, debido a una mayor experiencia o a un mejor posicionamiento de los candidatos que ocupan un cargo público a la hora de participar en elecciones, es decir, que son incumbentes.

La literatura sobre los efectos de la incumbencia surge en el campo de la ciencia política a principios de los años 70, principalmente en EE.UU., a partir de

1 En la práctica la mayoría de países imponen ciertas restricciones de edad y/o nacionalidad para poder optar a un cargo público. 
la observación recurrente de que los incumbentes en la Cámara de Representantes contaban con tasas de reelección muy altas. Ello era visto por algunos como el resultado de una desventaja en la competencia electoral, debido a los recursos y privilegios con los que cuenta alguien que ejerce un cargo público, en detrimento de otros competidores.

Dicho esto, una simple comparación estadística de los resultados electorales de incumbentes y no incumbentes no dice necesariamente mucho sobre el hecho de que ser incumbente represente una ventaja electoral, es decir, no se puede establecer directamente un efecto causal de que ser incumbente implique una ventaja electoral en la siguiente elección.

En particular, existe lo que Erikson (1971) reconoció como un problema de "relación causal recíproca". Gran parte de la diferencia en las tasas de reelección puede deberse a un efecto de selección: los incumbentes son por definición aquellos políticos que fueron más exitosos en la elección pasada, ya que son los que fueron más hábiles en captar el voto ciudadano requerido para ser elegidos. Si lo que los hace más exitosos (por ejemplo, habilidad, carisma, u otras características particulares del individuo) es persistente en el tiempo, a priori se espera que estos tengan mayores probabilidades de ser reelegidos si deciden participar en la siguiente elección.

Luego, la estimación de un efecto causal de la incumbencia requiere primero resolver este potencial problema de endogeneidad. La literatura reciente, principalmente Lee (2008), demuestra que la mejor manera de resolver este problema de identificación es utilizando una estrategia de regresión discontinua, que explote la discontinuidad inherente al sistema de votación por mayoría simple.

En específico se utiliza el hecho de que el estatus de incumbencia de un político es una función determinística del porcentaje de votos que este obtuvo durante la elección previa. A manera de ejemplo, bajo un escenario hipotético de solo dos candidatos, el ganador es aquel que obtuvo $50 \%+1$ de los votos, el punto de corte de la regla de asignación.

Siempre y cuando el porcentaje final de votos que obtengan los candidatos tenga elementos aleatorios en torno al punto de corte, se considera que en promedio, los candidatos que perdieron por un pequeño margen de votos constituyen un contrafactual válido de los candidatos que ganaron con un pequeño margen de votos y por lo tanto difieren únicamente en su estatus de tratamiento: la incumbencia.

A partir de ello, las inferencias causales provenientes de un diseño de regresión discontinua, bajo el cumplimiento de supuestos relativamente inocuos, pueden ser tan creíbles como las provenientes de un experimento aleatorio y por lo tanto constituyen, en este caso, la mejor estrategia econométrica disponible para la estimación de un efecto causal.

La estimación de un efecto incumbente es, en particular, pertinente para el caso de las elecciones municipales en Guatemala, ya que de acuerdo con la legislación vigente, el haber sido elegido como alcalde en ocasiones previas no constituye impedimento para optar a ejercer nuevamente el cargo.

Por otra parte, existe escasa literatura empírica sobre la dinámica de las elecciones municipales en Guatemala, limitándose esta en su mayoría a la descripción y análisis de los hechos estilizados. Por lo que un análisis de este tipo es un importante aporte 
a la literatura existente, especialmente hacia la comprensión de la dinámica electoral en elecciones locales.

El objetivo del presente trabajo se enfoca en responder la siguiente pregunta: ¿Es la incumbencia un activo para los políticos? En particular, ¿los recursos y privilegios inherentes a ejercer la posición de alcalde incrementan la probabilidad de que este sea reelegido si decide participar nuevamente en la próxima elección?

Además, el estudio de los candidatos a nivel individual nos permite analizar otros efectos de interés que han sido poco explorados, específicamente ¿cómo afecta la incumbencia las decisiones de optar a reelección y de cambiar de partido político en relación con las de otros candidatos?

A manera de comprender de mejor manera el rol de los partidos en las elecciones municipales, estas preguntas también se intentan responder para el caso en el que los partidos políticos, y no los candidatos individuales, son la unidad de análisis.

Para identificar el efecto causal de la incumbencia sobre las variables de interés mencionadas se adopta una estrategia econométrica de estimación de regresión discontinua como la discutida anteriormente, utilizando una base de datos con los resultados de elecciones municipales en Guatemala que abarcan cuatro períodos eleccionarios: 1999, 2003, 2007 y 2011.

Los resultados encontrados demuestran que lejos de ser una ventaja, la incumbencia parece ser una desventaja electoral. En promedio un alcalde incumbente tiene entre $14 \%$ y $18 \%$ menos de probabilidad de ser elegido en la próxima elección respecto de un no incumbente, este resultado es robusto a distintas especificaciones. La incumbencia también tiene efectos sobre las decisiones de los individuos de participar y cambiar de partido en elecciones sucesivas.

El resultado encontrado se extiende a los partidos políticos, lo que, contrario a lo propuesto por la literatura de partidos políticos en Guatemala, da un indicio de que la marca partidaria sí es relevante para los votantes. Adicionalmente ello implicaría que existe un traspaso parcial del efecto del performance del individuo al partido político.

Los resultados encontrados son consistentes con los encontrados por otros trabajos comparables sobre el efecto incumbente en países en desarrollo, principalmente Brasil, India y Ghana (Titiunik, 2009; Brambor y Ceneviva, 2011; Linden, 2004; y Uppal, 2009) y contrastan marcadamente con los efectos positivos y significativos encontrados en la literatura de estimación de efecto incumbente para EE.UU. (por ejemplo Lee, 2008; Broockman, 2009; Butler, 2009; Caughey y Sekhon, 2012; y Trounstine, 2011).

Sin embargo, a la fecha la literatura empírica ofrece poco en términos de explicaciones sobre la causa de la existencia de un efecto incumbente negativo. Por el momento solo se han ofrecido algunas especulaciones informales sobre las causas potenciales.

En la segunda parte del trabajo se intentan abordar empíricamente las posibles causas de un efecto incumbente negativo. Siguiendo la literatura teórica reciente, el trabajo de Klasnja (2011), propone la hipótesis de que en un contexto político-institucional débil con relativamente altos niveles de corrupción, como el de Guatemala y otros países en desarrollo, la capacidad de extracción de rentas de 
los incumbentes es creciente en el tiempo. Luego el efecto incumbente negativo surgiría como un intento de los votantes por limitar la búsqueda de rentas por parte de los políticos en el poder.

La hipótesis propuesta se testea indirectamente utilizando el rol de la conformación del Concejo Municipal en elecciones competitivas, principalmente el hecho de si el alcalde debe gobernar el municipio con un Concejo dividido o si cuenta con una mayoría.

Los resultados encontrados son mixtos, sin embargo dan cierta credibilidad a la hipótesis propuesta. Otros factores importantes también parecen estar en juego, particularmente el hecho de que las elecciones juegan un importante rol para descubrir el tipo (o calidad) de los políticos.

En general, el aporte del trabajo es relevante en dos dimensiones: por un lado se genera un importante aporte a la escasa literatura existente sobre elecciones municipales en Guatemala, brindando evidencia empírica sobre los efectos de la incumbencia y la dinámica de la democracia en el ámbito local, tanto desde la perspectiva de los votantes como de los candidatos a alcalde.

Por otro, se profundiza en la literatura sobre los efectos de la incumbencia en países en desarrollo, explorando empíricamente una posible explicación a la existencia de un efecto incumbente negativo, encontrándose resultados mixtos.

El trabajo se distribuye de la siguiente manera: la Sección 2 discute sobre el marco institucional de Guatemala e identifica algunos de los principales problemas que prevalecen en el sistema político y de partidos del país. La Sección 3 describe en detalle los problemas metodológicos de la estimación del efecto incumbente y detalla explícitamente la forma en que se planea abordar, en este caso mediante la estrategia de RDD. La Sección 4 discute brevemente la fuente de los datos y la forma en que se construyó la base de datos. La Sección 5 analiza los resultados de las estimaciones y propone una posible explicación teórica. La Sección 6 testea empíricamente las posibles causas de un efecto incumbente negativo y la Sección 7 concluye.

\section{MARCO INSTITUCIONAL}

A partir de 1985, luego de varias décadas de gobiernos autoritarios, Guatemala inicia su retorno a la democracia, mediante la aprobación de una nueva Constitución Política y la adopción de un sistema de gobierno presidencial.

De acuerdo con la administración política establecida en la Constitución, el país se subdivide en 22 departamentos y estos a su vez en 332 municipios. Basado en ello, las elecciones se realizan en tres niveles: presidencial, congresional (donde existe representación departamental y nacional), y finalmente el nivel local o municipal.

Inicialmente la Constitución estableció una duración del mandato electoral para el presidente y diputados de cinco años, con elecciones municipales a medio período para el caso de los alcaldes y el Concejo municipal.

No obstante una reforma constitucional llevada a cabo en 1994, aprobó un cambio en materia electoral, el que estableció que el mandato para presidente, diputados y autoridades municipales sería reducido uniformemente a cuatro años. De igual forma 
se acordó realizar todas las elecciones de forma simultánea, esto rigió a partir de las elecciones de 1999 y sigue vigente hasta la actualidad.

A la fecha se reconoce que todas las elecciones han transcurrido de forma libre y transparente. Ello se ha logrado gracias al fortalecimiento institucional del Tribunal Supremo Electoral, así como la amplia participación de observadores internacionales en todos los comicios, ello ha ayudado a legitimar el proceso de democratización del país.

No obstante, la debilidad del sistema de partidos políticos sigue siendo una preocupación (Sánchez, 2008). Desde el inicio de este proceso democrático ninguno de los partidos políticos ha logrado repetir una reelección a nivel presidencial, y por el contrario, una vez cumplido su período de gobierno, los partidos tienden a debilitarse y desaparecer.

Como evidencia Villamizar (2007), los partidos políticos se han caracterizado por una excesiva tasa de fecundidad y una baja esperanza de vida. En este entorno de débil institucionalidad partidaria, la identificación partidaria se reconoce como difusa y volátil, lo que dificulta a los ciudadanos el reconocimiento de las posiciones políticas de los candidatos y afecta su capacidad de realizar decisiones informadas a la hora de votar.

Especialmente a nivel municipal, la representación electoral se ha basado en formas personalizadas e individualistas de representación, y no a base de propuestas claras de política.

En la práctica, lo que ha prevalecido en el nivel local es la existencia de lo que Mack (2006) denomina liderazgos carismáticos, o figuras que han dominado la escena política local, muchas veces reeligiéndose como alcaldes utilizando distintos partidos políticos como plataforma.

Los partidos políticos, reconociendo esta realidad, han adoptado la estrategia de valerse del arraigo de los líderes locales a la hora de postular sus candidatos, siendo los mecanismos de elecciones primarias algo prácticamente inexistente. Ello parece explicar la debilidad institucional de los partidos políticos y la carencia de democracia en sus procesos internos a la hora de seleccionar sus candidatos.

Así mismo, este marco institucional personalista ha incrementado los incentivos que enfrentan los políticos para incurrir en actividades de rent-seeking en lugar de responder a las demandas del electorado (Mainwaring y Torcal, 2006).

Para el caso de las elecciones municipales, cada votante de forma voluntaria debe manifestar su preferencia por una lista partidaria, que incluye el candidato a alcalde y un listado de síndicos y concejales para conformar el Concejo Municipal. El alcalde y los síndicos se eligen por mayoría simple, mientras que los escaños para concejales se reparten mediante un sistema de representación proporcional, sobre la base de la cantidad de votos obtenidos por cada lista partidaria.

En la práctica este arreglo institucional, si bien ha favorecido una mayor representatividad, también ha tendido a generar muchos gobiernos locales divididos, ya que una importante cantidad de elecciones municipales se caracterizan por ser muy competitivas (Mack, 2006).

A partir de los Acuerdos de Paz firmados en 1996, y especialmente con las reformas al Código Municipal y la Ley de Descentralización aprobadas en 2002, se ha acelerado 
el proceso de descentralización, trasladándose progresivamente a las municipalidades mayores competencias administrativas, económicas, políticas y sociales.

No obstante, ese proceso no se ha visto acompañado de una mayor capacidad autónoma de recaudar ingresos fiscales para cumplir con estas nuevas obligaciones adquiridas. En la práctica las municipalidades aún dependen, tanto técnica como financieramente, del gobierno central (Gómez y Geffner, 2005).

En ese sentido, el descontento del electorado con la gestión política de los alcaldes ha llegado a niveles altos, y debido a las restricciones institucionales que limitan la capacidad de los ciudadanos de controlar y exigir la rendición de cuentas a los políticos, el voto parece ser la única alternativa con la que cuentan para disciplinar a los incumbentes.

Comprender este marco institucional y los incentivos vigentes, tanto para políticos como votantes, es clave para comprender los resultados del trabajo de estimación empírica que se pretende realizar, el que se detalla a continuación.

\section{METODOLOGIA EMPIRICA}

\subsection{Efecto incumbente: problemas de identificación}

La discusión en literatura sobre los efectos de la incumbencia surge en el campo de la ciencia política a principios de los años 70, principalmente en EE.UU., a partir de la observación recurrente de que los incumbentes en la Cámara de Representantes contaban con tasas de reelección muy altas.

Este hecho estilizado sobre los incumbentes en el Congreso generó la pregunta de si los representantes usan los privilegios y recursos con los que cuentan por el hecho de ejercer un cargo público para ganar ventaja electoral para sí mismos o sus partidos.

Esta conjetura suena plausible, sin embargo una simple comparación estadística de los resultados electorales de incumbentes y no incumbentes no necesariamente refleja una ventaja electoral producto de la incumbencia. Los incumbentes son por definición candidatos y partidos que han demostrado que pueden ganar una elección, y ello puede deberse a muchos factores.

Particularmente existe lo que Erikson (1971) reconoció como un problema de "relación causal recíproca". La diferencia en las tasas de reelección puede explicarse por un efecto de selección: si lo que hace más exitoso a los incumbentes (características generalmente no observables) es persistente en el tiempo, se espera que estos tengan una mayor ventaja electoral. Luego la estimación de un efecto causal de la incumbencia requiere primero resolver este potencial problema de endogeneidad.

Las medidas de incumbencia más comunes utilizadas por la literatura han sido las de sophomore surge y retirement slump. La primera es el promedio de votos obtenidos por un candidato que participa en una elección por primera vez como incumbente y la segunda es el promedio de votos que pierde el partido cuando el incumbente se retira y decide no participar en la próxima elección (Cover, 1977).

Por su parte, Gelman y King (1990) demostraron que ambas medidas se encontraban sesgadas y propusieron una medida alternativa: el índice Gelman-King, el que 
no estuvo exento de críticas, principalmente por no tomar en cuenta las características individuales del candidato y por basarse en supuestos cuestionables.

Levitt y Wolfram (1997) recalcaron que el estatus de incumbente se encuentra relacionado a la calidad y otras características individuales de los candidatos y la evaluación que estos realizan sobre sus probabilidades de ganar a la hora de decidir participar o no en la carrera electoral. Esta habilidad no es aleatoria, y por lo tanto las estimaciones que no resuelvan este problema de identificación darán estimaciones sesgadas de la ventaja electoral del incumbente.

\subsection{Regresión discontinua (RDD)}

Para lograr un experimento hipotético ideal que nos permitiera estimar el efecto de la incumbencia eliminando todo problema de endogeneidad, sería necesario observar al mismo candidato como incumbente y no incumbente en el mismo período; claramente esto no es factible.

Sin embargo la literatura reciente, particularmente Lee (2008), ha demostrado que la mejor alternativa para resolver el problema de identificación que conlleva la estimación del efecto causal de la incumbencia es la de utilizar una estrategia RDD, que explote la discontinuidad inherente al sistema de votación por mayoría simple.

El RDD parte de la premisa de que el resultado electoral es una función determinística de la proporción de votos obtenida por el candidato en la elección previa, la que está a su vez determinada por las características específicas del candidato y el electorado. Es decir, se espera que un candidato con mayor habilidad (o que ha invertido más recursos de campaña) obtenga una mayor proporción de votos que uno de baja habilidad.

Esta regla de asignación se caracteriza por la existencia de una discontinuidad o punto de corte, ello es esencial para la implementación de una estrategia de RDD. Por ejemplo, bajo un escenario hipotético de únicamente dos candidatos, el ganador es aquel que obtuvo $50 \%+1$ de los votos, el punto de corte de la regla de asignación.

En general, se espera que aquellos que logran ganar las elecciones, es decir ser incumbentes, sean sistemáticamente políticos con mayor experiencia y habilidad. Sin embargo se reconoce que siempre existe un componente de aleatoriedad en el resultado final de la elección. Por ejemplo, el día de las votaciones puede llover, con esto el clima puede reducir la asistencia a las urnas y por ende afectar de manera aleatoria los resultados finales de la votación.

Luego, siempre y cuando el porcentaje final de votos que obtengan los candidatos pueda ser afectado por elementos aleatorios en torno al punto de corte o discontinuidad, se considera que en promedio los candidatos que perdieron por un pequeño margen de votos constituyen un contrafactual válido de los candidatos que ganaron con un pequeño margen de votos y por lo tanto difieren únicamente en su estatus de tratamiento: la incumbencia.

A partir de ello, las inferencias causales provenientes de un diseño de regresión discontinua pueden ser tan creíbles como las provenientes de un experimento aleatorio y por lo tanto constituyen, en este caso, la mejor estrategia econométrica disponible para la estimación de un efecto causal. 
Es importante reconocer que la estrategia RDD al concentrarse en los resultados de elecciones competitivas y en particular en la ventana del punto de corte de la regla de asignación, los resultados de las estimaciones son una aproximación al efecto de la incumbencia para ese tipo particular de elecciones y no necesariamente es generalizable para la medición de un impacto fuera de dicho umbral.

Para que esta estrategia de identificación sea válida, el supuesto que debe cumplirse es que las variables características del individuo y/o del municipio, tanto observables como no observables, son continuas en el punto de corte dado por el límite entre ganar o perder las elecciones. Este supuesto puede testearse empíricamente (al menos en forma indirecta) comparando las variables de los distintos candidatos en torno al umbral; si la estrategia es válida, estas debiesen estar balanceadas en esa vecindad, es decir, no van a diferir sistemáticamente entre incumbentes y no incumbentes.

Debe cumplirse además que la regla de asignación no pueda ser controlada de forma sistemática por ninguno de los actores políticos. Es decir, la existencia de un fraude electoral invalidaría los resultados de esta estrategia de identificación, ya que se violaría el supuesto de aleatoriedad en torno al punto de corte o discontinuidad.

Como se mencionó, este ha sido un factor prácticamente ausente en las elecciones de Guatemala, gracias a la existencia de un importante grado de autonomía del Tribunal Supremo Electoral y un acompañamiento de observadores internacionales a lo largo de los distintos procesos eleccionarios, esto no constituye una preocupación para el presente trabajo.

Un factor relevante a tomar en cuenta a la hora de estimar el efecto incumbente para candidatos individuales (y no partidos políticos) utilizando una estrategia de RDD es la existencia de un potencial problema de reducción del tamaño de la muestra, producto de candidatos que deciden no participar en la próxima reelección. Luego no es posible observar qué hubiese pasado si hubiesen participado en la próxima elección, es decir, se cuenta con una muestra truncada.

Debido a que la decisión de optar o no a la reelección depende de la oportunidad que el candidato percibe de ganar la próxima reelección, existe un potencial problema de endogeneidad que podría sesgar la estimación del efecto incumbente si las tasas de reelección difieren sistemáticamente entre incumbentes y no incumbentes en torno a la vecindad del punto de corte.

Una potencial solución sugerida por McConell et al. (2008), que se adopta en este trabajo, es la de estimar la probabilidad incondicional que tiene el incumbente de ganar una reelección, aunque decida o no participar en la siguiente elección.

Existen diversas formas de implementar una estrategia de estimación empírica RDD, estas se revisan en Lee y Lemieux (2010). Para este trabajo, la variable de asignación del tratamiento se construye a partir de la diferencia de votos (como porcentaje de votos totales) entre el ganador y el perdedor de la elección; a causa de que se trabaja con datos de un sistema con múltiples partidos, es necesario definir esta variable de una forma alternativa a un sistema bipartidista como el de EE.UU., donde el punto de corte se cruza cuando un candidato obtiene más de $50 \%$ de los votos totales.

Particularmente para $j=1, \ldots, j$, sea $V_{i t, j}$ la proporción del voto obtenida por el candidato $j$ en la municipalidad $i$ en la elección $t$ y $V_{i t,(1)}, \ldots, V_{i t,(J)}$ el ordenamiento 
correspondiente de los resultados de la votación. El margen de victoria para el candidato $k$ se define como el porcentaje de voto obtenido por él, menos el porcentaje de voto obtenido por su oponente más sólido, definido este último como el candidato que obtuvo más votos en el caso en que $k$ haya perdido o el candidato que obtuvo el segundo mayor porcentaje de votos en el caso de que $k$ haya ganado la elección. Formalmente:

$$
Z_{i t, k}=\left\{\begin{array}{c}
V_{i t, k}-V_{i t,(J-1)} \text { si } V_{i t, k}=V_{i t,(J)} \\
V_{i t, k}-V_{i t,(J)} \text { en otro caso }
\end{array}\right.
$$

A partir de ello encontramos que la regla de asignación de la incumbencia del candidato $k$ en la municipalidad $i$, que se denota como $I_{i t, k}$, es:

$$
I_{i t, k}=\left\{\begin{array}{c}
1 \text { si } Z_{i t, k} \geq 0 \\
0 \text { si } Z_{i t, k}<0
\end{array}\right.
$$

Para nuestro análisis, el enfocarnos en el candidato a nivel individual nos permite considerar varios casos de interés dentro del marco de la estrategia RDD: (i) la probabilidad (incondicional) de que el candidato $k$ gane la elección en la elección $t+1$, (ii) la probabilidad de que el candidato $k$ decida participar en la elección $t+1$ y (iii) la probabilidad de que el candidato $k$ compita bajo un partido distinto en la elección $t+1$.

Entonces, sea $Y_{i t+1, k}$ nuestra variable de interés, se propone estimar los parámetros de interés de dos maneras distintas:

La primera especificación empírica sigue al trabajo de Lee (2008) y Porter (2003), entre otros, al usar la muestra entera, permitiendo una relación flexible entre el resultado y el margen de victoria:

$$
Y_{i t+1, k}=\mu_{i}+\alpha_{k} \cdot 1\left\{Z_{i t, k} \geq 0\right\}+m\left(Z_{i t, k}\right)+\epsilon_{i t+1, k}
$$

Donde $Z_{i t, k}$, el margen de victoria del candidato, es la variable de asignación y $m\left(Z_{i t, k}\right)$ es una función de control que se especifica como un polinomio de distintos grados en $Z_{i t, k}$ así como su interacción con la variable dummy de incumbencia $I_{i t, k}{ }^{2}$. Adicionalmente se incorporan efectos fijos por municipio $\mu_{i}$. Si la especificación es correcta, la estimación del parámetro de interés $\alpha_{k}$ será consistente.

2 La función de control se espeficia de la siguiente manera: $m\left(Z_{i t, k}\right)=\beta_{01} Z_{i t, k}+\beta_{01} Z_{i t, k}^{2}+\ldots+$ $\beta_{0 p} Z_{i t, k}^{p}+\beta_{1} I_{i t, k} Z_{i t, k}+\beta_{1} I_{i t, k} Z_{i t, k}^{2}+\ldots+\beta_{p} I_{i t, k} Z_{i t, k}^{p}$. 
La segunda se basa en los métodos de regresión discontinua no paramétrica descritos por Lee y Lemieux (2009). Para ello se estima una regresión linear local a ambos lados del punto de corte, utilizando un kernel triangular. Ello garantiza que el peso que tiene cada observación dentro de la regresión sea menor según se aleja de la vecindad del punto de corte. La elección del ancho de banda para la regresión no paramétrica se realiza a base de la regla de Imbens y Kalyanaraman (2012).

\section{DATOS}

Utilizando datos para Guatemala construimos una base de datos a nivel municipal con los resultados de las votaciones en elecciones de alcalde, desagregando los resultados para cada candidato y partido político. Los datos fueron obtenidos de las memorias electorales del Tribunal Supremo Electoral para cuatro períodos eleccionarios: 1999, 2003, 2007 y 2011.

Al momento de las elecciones municipales de 1999, las primeras de la muestra, Guatemala se encontraba conformada por 330 municipios, no obstante para las elecciones del 2011 este número había aumentado a 333.

Tres nuevos municipios fueron creados de forma posterior a las elecciones de 1999, a partir del fraccionamiento territorial de tres municipios ya existentes ${ }^{3}$. Con el objetivo de asegurar que los resultados sean comparables para elecciones sucesivas, se eliminaron de la muestra los tres nuevos municipios, así como los otros tres municipios a partir de los cuales estos fueron fraccionados. Con este ajuste la base de datos se reduce al análisis de resultados electorales en 327 municipios.

Para poder identificar los resultados de los candidatos en el tiempo, realizamos un match para cada candidato por municipio entre los resultados de distintos períodos eleccionarios sucesivos; a partir de ello es posible observar si los candidatos ganaron o no, si optan por la reelección y si participan bajo el mismo partido o si cambian de partido en distintos períodos eleccionarios. La muestra resultante es de 7.049 observaciones.

Finalmente se creó una variable dummy que toma el valor 1 si el candidato es incumbente en la elección $t$ y vuelve a ganar la elección en $t+1$. Como se mencionó anteriormente, se asume que los candidatos que no participaron en la próxima elección perdieron, obteniéndose de esta manera la probabilidad incondicional de ganar la próxima elección.

Para las estimaciones, todas las observaciones se agrupan en pares de elecciones consecutivas que permiten comparar el resultado obtenido por cada candidato en la elección del período $t$ con el resultado obtenido por el mismo candidato en la elección del período $t+1$.

3 El 11 de noviembre de 1999 se decreta la creación del municipio de La Tinta, previamente perteneciente al municipio de Panzós. Luego, en agosto del 2005 se establece la creación del municipio de Unión Cantinil, previamente parte del municipio de Chiantla. En febrero de 2008, Raxruhá, previamente perteneciente al municipio de Chisec, adquiere categoría legal de municipio. 
El Cuadro 1 presenta los principales hechos estilizados en torno a resultados electorales de interés y otras características predeterminadas (antes de la elección en el período $t$ ) de los candidatos individuales. En esta Tabla se comparan los promedios de las variables según la variación en el estatus de incumbencia.

La primera y segunda columnas utilizan información de toda la muestra, mientras que tercera y cuarta columnas solo muestran la información para elecciones competitivas, en ellas la diferencia de votos obtenidas entre los ganadores y perdedores fue menor o igual al $5 \%$ de los votos.

Se realiza un test- $t$ de diferencias en medias para identificar si la distribución de estas variables es significativamente distinta para las dos muestras (incumbentes y no incumbentes). Lo que se busca es que exista continuidad en las características predeterminadas según se reduce la muestra, prestando validez al diseño de la regresión discontinua.

Como se observa en la primera fila, en general existen tasas bajas de elección, no superando estas el $30 \%$, siendo ello una característica inherente al sistema político volátil y dinámico de Guatemala. Los incumbentes se reeligen en promedio $29 \%$, mientras que los no incumbentes muestran una tasa promedio de elección del $5 \%$.

A pesar de ello, cuando se reduce la muestra a elecciones competitivas los incumbentes muestran una desventaja en la tasa de reelección en torno al 7\%. Ambas diferencias son estadísticamente significativas, lo que nos da un primer indicio de la existencia de un efecto incumbente negativo.

\section{CUADRO 1}

\section{RESULTADOS ELECTORALES Y CARACTERISTICAS PREDETERMINADAS: CANDIDATOS GANADORES VS. PERDEDORES}

\begin{tabular}{|lcccccc|}
\hline & \multicolumn{2}{c}{ Toda la muestra } & & \multicolumn{2}{c|}{ IMargenl $<0,05$} \\
\cline { 2 - 3 } \cline { 5 - 6 } & Incumbente & $\begin{array}{c}\text { No } \\
\text { incumbente }\end{array}$ & & Incumbente & $\begin{array}{c}\text { No } \\
\text { incumbente }\end{array}$ \\
\hline Gana en $t+1$ & $0,292^{*}$ & $0,053^{*}$ & & $0,216^{*}$ & $0,283^{*}$ \\
Participa en $t+1$ & $0,710^{*}$ & $0,278^{*}$ & & 0,687 & 0,673 \\
Pertenece a partido del presidente en $t$ & & $0,331^{*}$ & $0,103^{*}$ & & 0,280 & 0,281 \\
Pertenece a coalición del presidente en $t$ & & $0,492^{*}$ & $0,252^{*}$ & & 0,461 & 0,477 \\
Participa en elecciones a diputado en $t+1$ & 0,024 & & 0,021 & & 0,013 & 0,014 \\
Diferencia en votos (\%) & $-0,080^{*}$ & $0,009^{*}$ & & $-0,040^{*}$ & $-0,007^{*}$ \\
Cambia de partido en $t+1$ & $0,489^{*}$ & $0,694^{*}$ & & $0,486^{*}$ & $0,597 *$ \\
Pr (Gana en $t+1$ I participa) & $0,412^{*}$ & $0,192^{*}$ & & $0,314^{*}$ & $0,421^{*}$ \\
\hline
\end{tabular}

Nota: Se realiza un test- $t$ de diferencias en medias entre individuos ganadores y perdedores en la elección $t$, las variables marcadas con un asterisco son significativas de acuerdo con este test. Las primeras dos columnas utilizan información de la muestra completa, mientras que para las últimas dos se reduce el tamaño de la muestra para tomar en cuenta únicamente elecciones competitivas. 
Otra variable interesante de explorar es si los candidatos de la elección $t$ participan en elecciones a diputados en la elección $t+1$. Se puede observar que no existen diferencias importantes según el estatus de incumbencia y en general es muy baja la probabilidad de que un individuo que participó en una elección a alcalde decida postularse como diputado en la elección siguiente.

Las últimas tres filas presentan resultados electorales condicionales en que el candidato decida participar en la siguiente elección. En virtud de esa condicionalidad, es muy probable la existencia de un sesgo de selección en la muestra, especialmente si la probabilidad de que un individuo decida participar en la siguiente elección se ve influenciada por su condición de ganador o perdedor en la elección pasada.

Finalmente, como un test adicional de la validez de la estrategia de estimación utilizada se implementó el test de densidad de McCrary (McCrary, 2008), cuyo resultado gráfico se presenta en la Figura 1. Como se puede observar no existe evidencia de manipulación de la variable de interés en torno al punto de corte, esto presta credibilidad adicional a la estrategia de identificación utilizada.

\section{FIGURA 1}

TEST DE DENSIDAD DE McCRARY

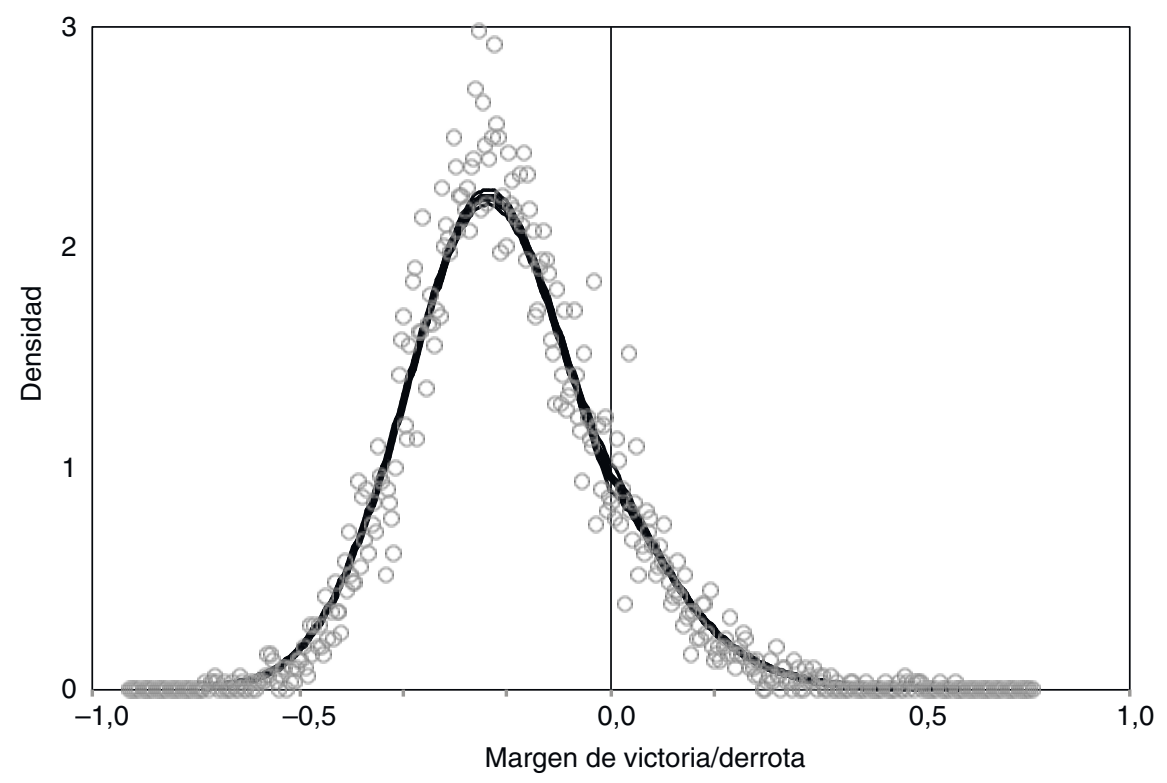

Estimador de discontinuidad: 0,1528 $(0,0977)$ 


\section{RESULTADOS}

\subsection{Efecto incumbente a nivel individual}

La Figura 2a muestra gráficamente el efecto incumbente negativo mencionado anteriormente. Cada punto del gráfico representa el promedio local de los datos, agrupados en 150 celdas o bins. El eje horizontal representa el margen con el que los candidatos ganaron o perdieron la elección en el período $t$, mientras que el eje vertical representa la proporción de candidatos que ganaron la elección en el período $t+1$ a causa del margen de votos obtenidos en la elección pasada.

Las observaciones más hacia la izquierda representan a candidatos que perdieron con un mayor margen de votos la elección en $t$, y como se observa, en promedio su probabilidad de ganar la elección en $t+1$ es muy baja. Al contrario, las observaciones más hacia la derecha representan a candidatos que ganaron la elección en $t$ con un margen amplio y con ello su probabilidad de ganar en el período $t+1$ es considerablemente alta.

Particularmente de nuestro interés es la línea punteada vertical centrada en el valor cero del eje horizontal, esta constituye la discontinuidad o punto de corte en la regla de asignación. Los puntos a la derecha de esta son los que ganaron la elección en $t$ y por lo tanto recibieron tratamiento, es decir, son incumbentes; mientras que los puntos a la izquierda son los candidatos que perdieron la elección y por lo tanto constituyen el grupo de los no incumbentes.

Porque en este caso se cumplen los supuestos que prestan validez a nuestra estrategia de RDD, podemos decir que en promedio, en torno a la vecindad de la discontinuidad en la regla de asignación, los puntos marginalmente a la izquierda de esta constituyen un contrafactual válido de los puntos marginalmente a la derecha de esta. Por lo tanto la comparación de las diferencias en los resultados de la elección en el período de $t+1$ entre estos puntos nos aproxima a un efecto causal de la incumbencia.

Como se puede observar, en el límite del punto de corte existe una discontinuidad que se refleja en una caída en torno a $8 \%$, lo que nos indica que los individuos que ganan la elección por un margen muy estrecho tienen una menor probabilidad de ganar en la siguiente elección en comparación a individuos que perdieron por un estrecho margen.

La Figura $2 b$ presenta un gráfico análogo al anterior para la probabilidad de que el individuo decida participar en la próxima elección. Como se observa, existe un salto negativo en el punto de corte, sin embargo es muy reducido. Podemos decir que en la vecindad del punto de corte la probabilidad de participar en la siguiente elección no difiere sistemáticamente entre ganadores y perdedores. Ello es consistente con lo encontrado en el Cuadro 1.

En el Cuadro 2 se muestran los resultados de las regresiones paramétricas y no paramétricas que estiman el efecto incumbente para tres distintas variables de interés: (i) La probabilidad (incondicional) de ganar la elección en $t+1$, (ii) la probabilidad 


\section{FIGURA 2A}

PROBABILIDAD DEL CANDIDATO DE SER ELEGIDO EN LA ELECCION $t+1$ SEGUN SU MARGEN DE VICTORIA/DERROTA EN LA ELECCION $t$ : PROMEDIOS LOCALES CON 150 BINS Y UN AJUSTE NO PARAMETRICO

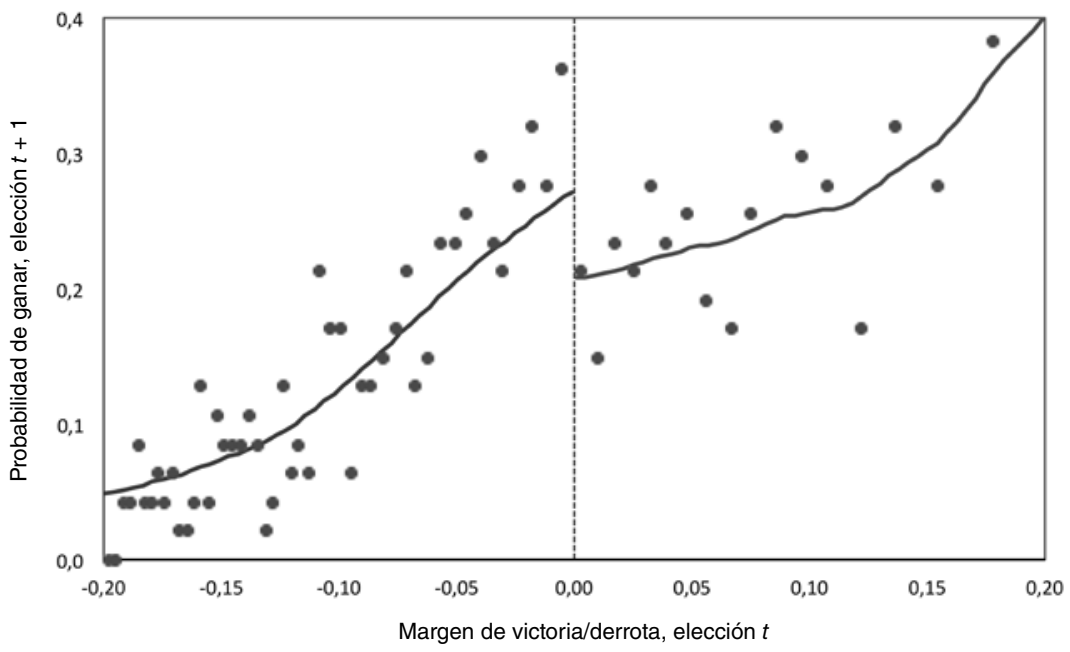

\section{FIGURA 2B}

PROBABILIDAD DEL CANDIDATO DE PARTICIPAR EN LA ELECCION $t+1$ SEGUN SU MARGEN DE VICTORIA/DERROTA EN LA ELECCION $t$ : PROMEDIOS LOCALES CON 150 BINS Y UN AJUSTE NO PARAMETRICO






\section{CUADRO 2}

EFECTO INCUMBENTE A NIVEL INDIVIDUAL, 1999-2011

\begin{tabular}{|c|c|c|c|c|c|c|}
\hline & & & D Polinomic & & & \\
\hline & Lineal & Cuadrático & Cúbico & Cuártico & Quíntico & $\begin{array}{c}\text { No } \\
\text { paramétrico }\end{array}$ \\
\hline & $(1)$ & (2) & (3) & (4) & (5) & (6) \\
\hline Panel A: Probabi & le ganar elec & ión en $t+1$ & & & & \\
\hline Incumbente en $t$ & $\begin{array}{l}-0,0229 \\
(0,0255)\end{array}$ & $\begin{array}{c}-0,112 * * * * \\
(0,0350)\end{array}$ & $\begin{array}{c}-0,129 * * * \\
(0,0446)\end{array}$ & $\begin{array}{c}-0,138^{* *} \\
(0,0543)\end{array}$ & $\begin{array}{c}-0,182 * * * * \\
(0,0638)\end{array}$ & $\begin{array}{c}-0,141 * * * \\
(0,0401)\end{array}$ \\
\hline Observaciones & 7.049 & 7.049 & 7.049 & 7.049 & 7.049 & 7.049 \\
\hline R-cuadrado & 0,189 & 0,202 & 0,205 & 0,206 & 0,206 & \\
\hline Panel B: Probabi & le participar & nelección $t$ & & & & \\
\hline Incumbente en $t$ & $\begin{array}{c}0,124 * * * \\
(0,0260)\end{array}$ & $\begin{array}{l}-0,0325 \\
(0,0348)\end{array}$ & $\begin{array}{c}-0,103 * * \\
(0,0431)\end{array}$ & $\begin{array}{c}-0,113^{* *} \\
(0,0514)\end{array}$ & $\begin{array}{c}-0,140 * * \\
(0,0594)\end{array}$ & $\begin{array}{c}-0,0851 * \\
(0,0442)\end{array}$ \\
\hline Observaciones & 7.049 & 7.049 & 7.049 & 7.049 & 7.049 & 7.049 \\
\hline R-cuadrado & 0,226 & 0,240 & 0,243 & 0,243 & 0,244 & \\
\hline Panel C: Probabi & le cambiar d & partido en e & ección $t+1$ & & & \\
\hline Incumbente en $t$ & $\begin{array}{c}-0,00353 \\
(0,0268)\end{array}$ & $\begin{array}{c}-0,0866^{* * *} \\
(0,0367)\end{array}$ & $\begin{array}{c}-0,134 * * * \\
(0,0466)\end{array}$ & $\begin{array}{c}-0,111 \text { *** } \\
(0,0364)\end{array}$ & $\begin{array}{c}-0,137 * * \\
(0,0650)\end{array}$ & $\begin{array}{c}-0,102 * * \\
(0,0418)\end{array}$ \\
\hline Observaciones & 7.049 & 7.049 & 7.049 & 7.049 & 7.049 & 7.049 \\
\hline R-cuadrado & 0,104 & 0,110 & 0,111 & 0,111 & 0,112 & \\
\hline
\end{tabular}

Todas las regresiones incluyen efectos fijos por municipio. Errores estándar robustos (en paréntesis) se calculan a base de clusters al nivel de municipio-elección.

$* * * \mathrm{p}<0,01 ; * * \mathrm{p}<0,05 ; * \mathrm{p}<0,1$.

de participar en la siguiente elección y (iii) la probabilidad (incondicional) de que el candidato participe por un partido distinto al de la elección $t$ en la elección en $t+1^{4}$.

La Figura 3 muestra las estimaciones no paramétricas calculadas para distintos anchos de banda en torno a los presentados en el Cuadro 2, a manera de testear la sensibilidad de los resultados. De acuerdo con lo anticipado, un menor ancho de banda muestra una ganancia en reducción de sesgo del estimador, sin embargo aumenta la varianza del mismo. De igual forma, un incremento del ancho de banda implica una reducción de la varianza del estimador, pero a costa de introducir un mayor sesgo.

En general en el Panel $A$ se observa que un incumbente tiene en promedio entre $13 \%$ y $18 \%$ menos de probabilidad que un no incumbente de ser elegido en la próxima

4 Utilizando el criterio de información de Akaike, para el caso de la regresión paramétrica, en todos los casos se encuentra que las mejores regresiones son las que cuentan con un orden de polinomio de grado entre 3 y 5 , por lo que para la discusión de los resultados que se realiza a continuación nos concentramos específicamente en estos y en la regresión no paramétrica. 
elección. Este resultado es similar para distintas estimaciones y es significativo a lo largo de las mismas, por lo que podemos decir que es robusto. A partir de ello encontramos que lejos de ser una ventaja, la incumbencia per se implica una desventaja en términos electorales.

Este resultado es similar para el caso de la regresión no paramétrica, como se observa en la Figura 3a. La significancia del estimador es robusta a la especificación de distintos anchos de banda y los resultados son de una magnitud similar a los del caso paramétrico.

A su vez, el Panel $B$ muestra que la probabilidad de que un político incumbente decida participar en la próxima elección es menor que la de un no incumbente; la diferencia en magnitud (en torno a 8\%-14\% menos) es importante. Podríamos decir que este resultado es consistente con el resultado encontrado anteriormente, ya que si un incumbente conoce que su probabilidad de ser reelegido es menor, decidir no participar (y por ende no tener que invertir recursos en hacer campaña política) es una estrategia racional.

No obstante, el resultado muestra algunas señales de ambigüedad. Ello se aprecia de mejor manera en la Figura 3b, a tenor de que un incremento en el ancho de banda apunta a una pérdida de significancia del estimador, aunque el resultado probablemente esté afectado por un incremento en el sesgo.

Es importante destacar que si las tasas de reelección de incumbentes y no incumbentes difieren sistemáticamente, los resultados de estimaciones condicionales en la decisión de participar estarán sesgados, ya que las decisiones de participar estarán afectadas por la incumbencia, lo que nos genera un sesgo de selección. En ese sentido, el resultado encontrado avala nuestra decisión de estudiar la probabilidad "incondicional" de ser reelegido.

Otro factor importante en la dinámica política nacional ha sido la práctica del "transfuguismo", entendiéndose por esta la decisión de un político de cambiar de partido a otro por el que fue elegido o participó en la elección inicial. La recurrencia de esta práctica ha sido considerada por algunos autores como evidencia de la alta volatilidad y la irrelevancia de los partidos políticos en el país, sin embargo Fortin (2010) argumenta que la decisión de migrar de un partido a otro obedece a un cálculo racional (costo/beneficio) que realiza el político para maximizar su probabilidad de reelección.

Siguiendo esa lógica, las regresiones del Panel $C$ muestran que la incumbencia afecta la decisión de los individuos de participar en la siguiente elección con un partido político distinto al de la elección anterior; específicamente, los alcaldes elegidos con estrecho margen deciden con 10\%-13\% menos de probabilidad cambiar de partido.

Este resultado también se extiende al caso no paramétrico, como se observa en la Figura 3c, y podría estar reflejando el hecho de que cambiar de partido conlleva asociado un costo de transacción y/o un voto de castigo, y este probablemente es más alto (por la visibilidad del cambio de partido) para alcaldes que se encuentran en el poder que para otros candidatos que no ganaron la elección.

El Cuadro 3 muestra las regresiones utilizando información condicional en la decisión de participar en la siguiente elección; es decir, se analiza lo que ocurre 


\section{FIGURA 3}

ESTIMACIONES NO PARAMETRICAS UTILIZANDO DISTINTOS ANCHOS DE BANDA EN UNA VENTANA EN TORNO AL ANCHO DE BANDA OPTIMO

(a)



(b)

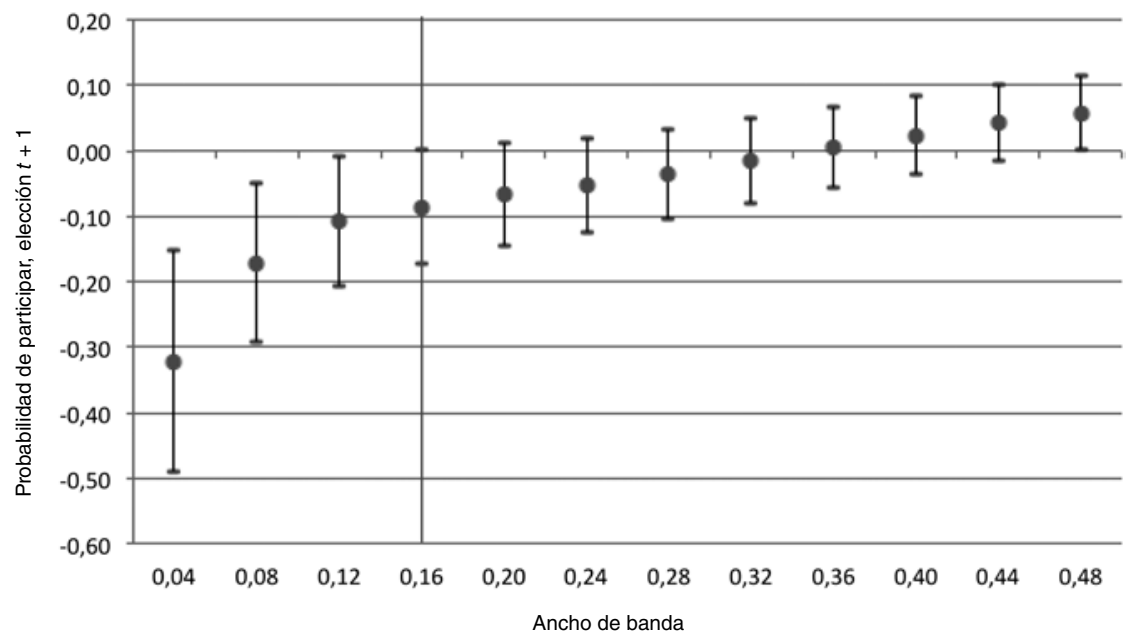


(c)

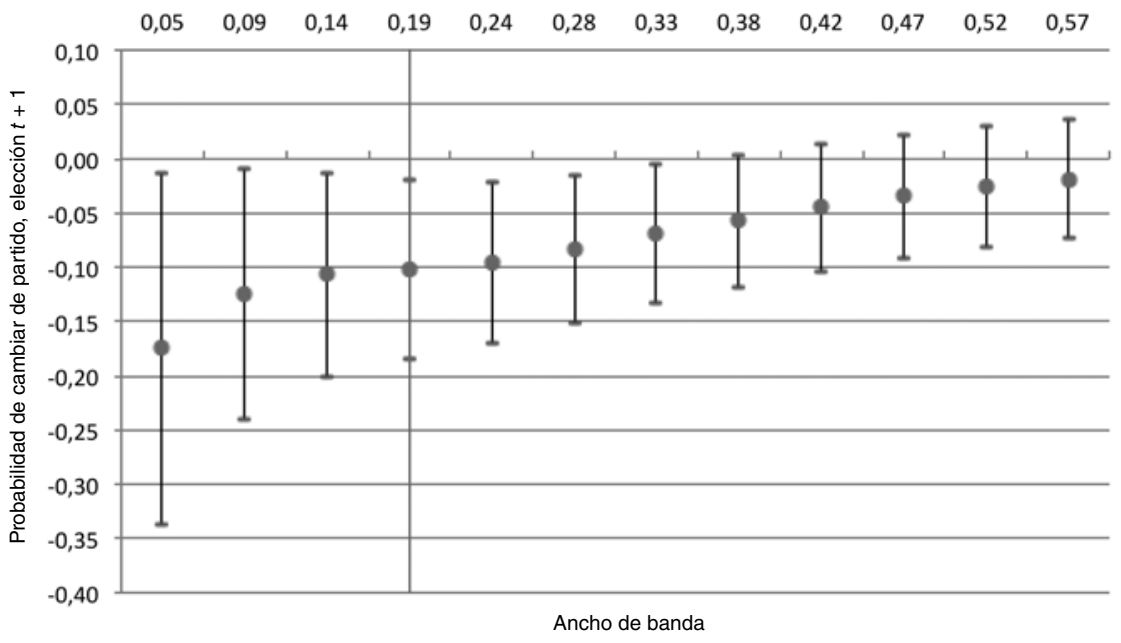

Nota: Las líneas negras representan el intervalo de confianza de los estimadores y la línea gris el estimador óptimo de Imbens y Kalyanaraman (2012).

únicamente con candidatos que participaron en la elección $t$ y deciden participar nuevamente en la elección $t+1$. Por lo tanto, debido a que ya encontramos que la decisión de reelección se ve afectada por la incumbencia, los estimadores entregados estarán sesgados. Aun así es interesante conocer algunos efectos.

Para el caso de la probabilidad condicional de ganar la elección en $t+1$ (Panel A), encontramos que el efecto de la incumbencia es negativo en torno a $17 \%$, ello no difiere de manera muy importante con el resultado encontrado para el caso de la probabilidad incondicional. El efecto es considerablemente robusto, mostrando la Figura 4a un patrón estable y magnitudes similares para las regresiones no paramétricas.

En el caso de la proporción del voto obtenido en la siguiente elección (Panel $B$ ), el resultado puede estar afectado por dos factores: primero, el sesgo inherente a la estimación condicional y, segundo, el hecho de que es una variable que también se ve afectada por la cantidad de candidatos compitiendo en una elección, lo que es altamente variable entre distintos períodos de elecciones. Por ello encontramos un efecto negativo, sin embargo no es estadísticamente significativo tanto en el caso paramétrico como en el no paramétrico.

Por último la probabilidad condicional de cambiar de partido (Panel C) muestra también un efecto incumbente negativo, sin embargo no es estadísticamente significativo mediante las distintas especificaciones, esto puede explicarse debido al hecho de que en este caso no se controla por el sesgo de selección. 


\section{CUADRO 3}

EFECTO INCUMBENTE A NIVEL INDIVIDUAL, 1999-2011

\begin{tabular}{|c|c|c|c|c|c|c|}
\hline & \multicolumn{5}{|c|}{ RD Polinomial } & \multirow{2}{*}{$\begin{array}{c}\mathrm{RD} \\
\text { No } \\
\text { paramétrico }\end{array}$} \\
\hline & Lineal & Cuadrático & Cúbico & Cuártico & Quíntico & \\
\hline & $(1)$ & $(2)$ & (3) & (4) & $(5)$ & $(6)$ \\
\hline \multicolumn{7}{|c|}{ Panel A: Probabilidad (ganar elección en $t+1 \mid$ participa) } \\
\hline Incumbente en $t$ & $\begin{array}{c}-0,147 * * * \\
(0,0398)\end{array}$ & $\begin{array}{c}-0,195^{* * *} \\
(0,0536)\end{array}$ & $\begin{array}{c}-0,179 * * \\
(0,0695)\end{array}$ & $\begin{array}{c}-0,167 * * \\
(0,0840)\end{array}$ & $\begin{array}{l}-0,178^{*} \\
(0,0988)\end{array}$ & $\begin{array}{c}-0,172 \text { *** } \\
(0,0542)\end{array}$ \\
\hline Observaciones & 2.387 & 2.387 & 2.387 & 2.387 & 2.387 & 2.387 \\
\hline R-cuadrado & 0,236 & 0,240 & 0,240 & 0,240 & 0,240 & \\
\hline \multicolumn{7}{|c|}{ Panel B: Proporción del voto obtenido en elección $t+1$} \\
\hline Incumbente en $t$ & $\begin{array}{c}-0,0444 * * * \\
(0,00962)\end{array}$ & $\begin{array}{c}-0,0315^{* * * *} \\
(0,0121)\end{array}$ & $\begin{array}{l}-0,0192 \\
(0,0153)\end{array}$ & $\begin{array}{c}-0,00998 \\
(0,0181)\end{array}$ & $\begin{array}{c}-0,00236 \\
(0,0205)\end{array}$ & $\begin{array}{l}-0,0198 \\
(0,0145)\end{array}$ \\
\hline Observaciones & 2.387 & 2.387 & 2.387 & 2.387 & 2.387 & 2.387 \\
\hline R-cuadrado & 0,547 & 0,549 & 0,550 & 0,551 & 0,551 & \\
\hline \multicolumn{7}{|c|}{ Panel C: Probabilidad (cambiar de partido en elección $t+1 \mid$ participa) } \\
\hline Incumbente en $t$ & $\begin{array}{c}-0,0942 * * \\
(0,0403)\end{array}$ & $\begin{array}{l}-0,0826 \\
(0,0540)\end{array}$ & $\begin{array}{l}-0,0785 \\
(0,0679)\end{array}$ & $\begin{array}{l}-0,0879 \\
(0,0559)\end{array}$ & $\begin{array}{l}-0,0768 \\
(0,0971)\end{array}$ & $\begin{array}{l}-0,0756 \\
(0,0553)\end{array}$ \\
\hline Observaciones & 2.387 & 2.387 & 2.387 & 2.387 & 2.387 & 2.387 \\
\hline R-cuadrado & 0,178 & 0,178 & 0,178 & 0,178 & 0,179 & \\
\hline
\end{tabular}

Todas las regresiones incluyen efectos fijos por municipio. Errores estándar robustos (en paréntesis) se calculan a base de clusters al nivel de municipio-elección.

$* * * \mathrm{p}<0,01 ; * * \mathrm{p}<0,05 ; * \mathrm{p}<0,1$.

A continuación se analiza la incumbencia desde la perspectiva de los partidos políticos, con el objetivo de determinar cuál es su relevancia en el sistema político de Guatemala.

\section{2. ¿Son los partidos políticos relevantes?}

Gran parte de la literatura sobre el sistema de partidos políticos en Guatemala parece afirmar que los partidos son muy volátiles y tienen muy poca relevancia, especialmente en elecciones municipales (p.ej. Sánchez, 2008). Lo importante parece ser el carisma del candidato en obtener el voto de los electores. De ser esto completamente cierto, los partidos proveen poca información al votante, y por lo tanto este debiese votar únicamente a base de la performance del individuo y no el del partido.

En la práctica, Mack y Sonnleitner (2006) encuentran que las reelecciones partidarias han sido un fenómeno relativamente frecuente en elecciones municipales, 
FIGURA 4

ESTIMACIONES NO PARAMETRICAS UTILIZANDO DISTINTOS ANCHOS DE BANDA EN UNA VENTANA EN TORNO AL ANCHO DE BANDA OPTIMO

(a)

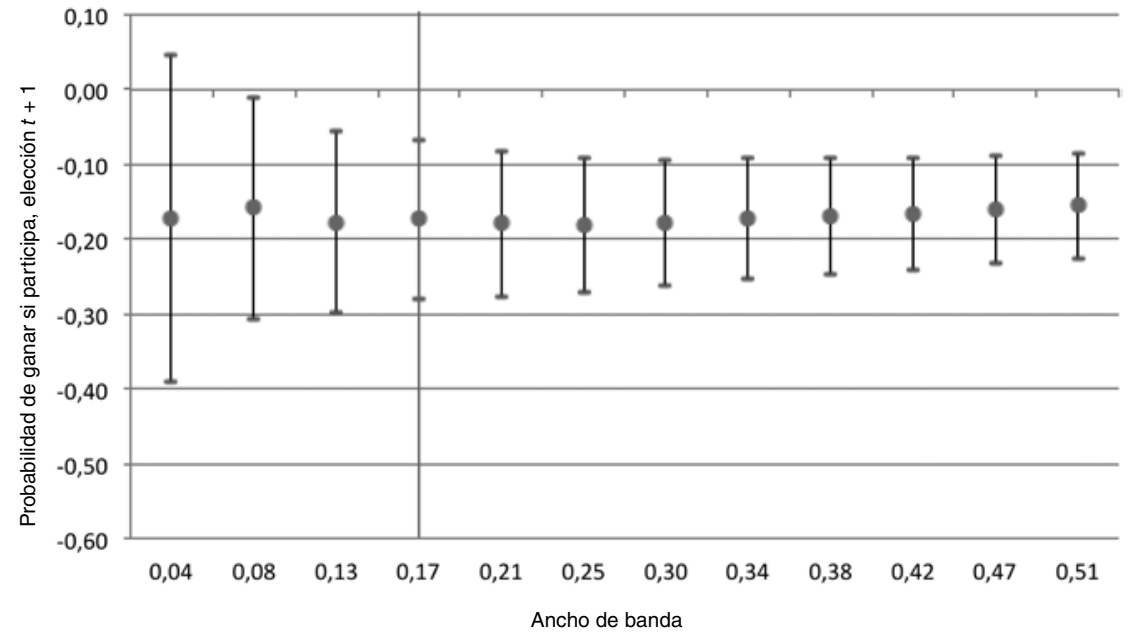

(b)

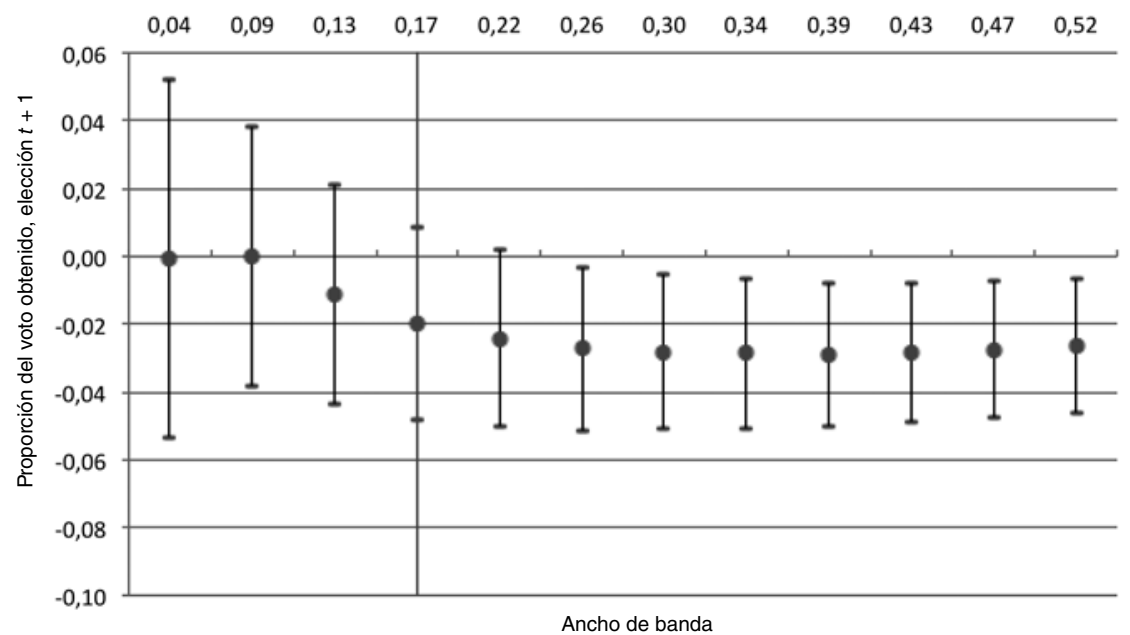


(c)



Nota: Las líneas negras representan el intervalo de confianza de los estimadores y la línea gris el estimador óptimo de Imbens y Kalyanaraman (2012).

aunque han perdido relevancia en los últimos años. En ese sentido, la marca partidaria sí parece transmitir algún tipo de información al votante y por lo tanto tiene al menos una importancia parcial a la hora de emitir el voto.

Para el caso de esta investigación, si los partidos no fuesen relevantes, no debiésemos encontrar la existencia de un efecto incumbente a nivel partidario, ya que de acuerdo con los datos de la muestra, aproximadamente el $80 \%$ de los partidos que participan en una reelección lo hacen con un candidato distinto al de la elección pasada.

Si el votante únicamente utilizara como criterio de decisión la actuación del individuo incumbente, no debiésemos observar ningún efecto sistemático cuando la unidad de análisis es el partido político y no el candidato, ya que la información relevante para el votante sería únicamente la del candidato y no la del partido y como hemos visto anteriormente estos generalmente difieren entre períodos eleccionarios debido a la frecuente práctica de transfuguismo o cambio de partidos.

Para testear esto, analizamos si existe un efecto incumbente sobre la probabilidad incondicional de ser elegido en la próxima elección. En este caso la unidad de análisis es el partido político en el tiempo, independientemente de si mantuvo el mismo candidato o si postuló a uno distinto en elecciones sucesivas.

La Figura 5a muestra la probabilidad de que el partido político sea elegido en la elección $t+1$ en función del margen de victoria/derrota que obtuvo en la elección $t$. Como en el caso individual, encontramos que existe una caída después del punto de corte (en el límite donde cambia el estatus de incumbencia), sin embargo esta no es tan pronunciada como la encontrada en la Figura 2a. 


\section{FIGURA 5A}

PROBABILIDAD DE QUE EL PARTIDO SEA ELEGIDO EN LA ELECCION $t+1$ SEGUN SU MARGEN DE VICTORIA/DERROTA EN LA ELECCION $t$ : PROMEDIOS LOCALES CON 150 BINS Y UN AJUSTE NO PARAMETRICO

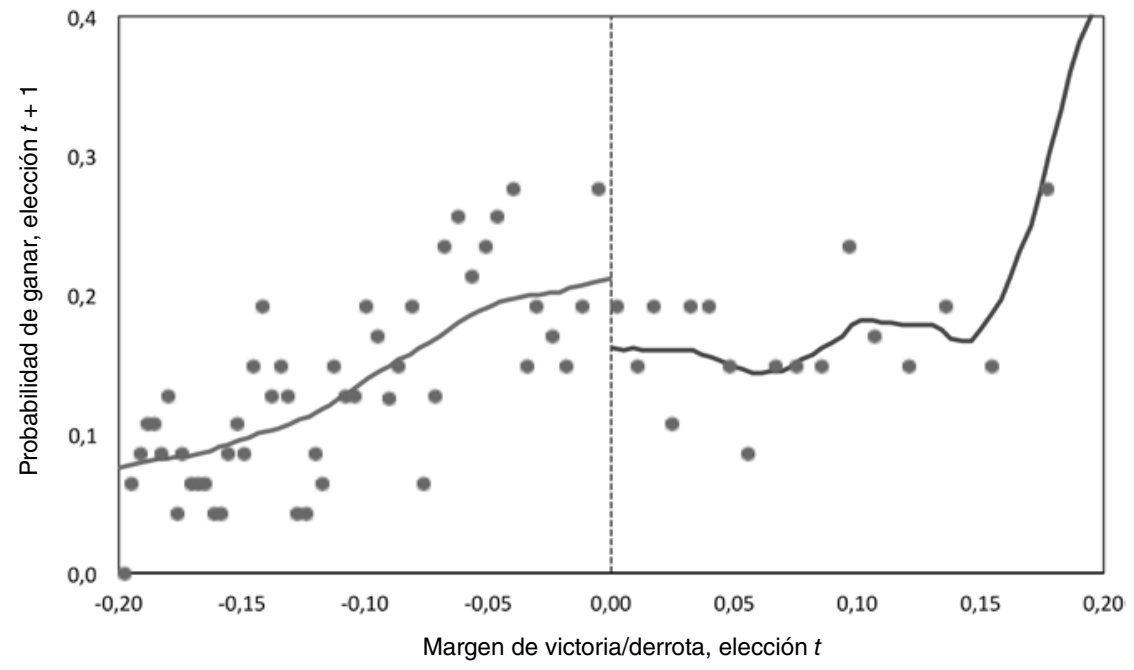

FIGURA 5B

PROBABILIDAD DE QUE EL PARTIDO DECIDA PARTICIPAR EN LA ELECCION $t+1$ SEGUN SU MARGEN DE VICTORIA/DERROTA EN LA ELECCION $t$ : PROMEDIOS LOCALES CON 150 BINS Y UN AJUSTE NO PARAMETRICO

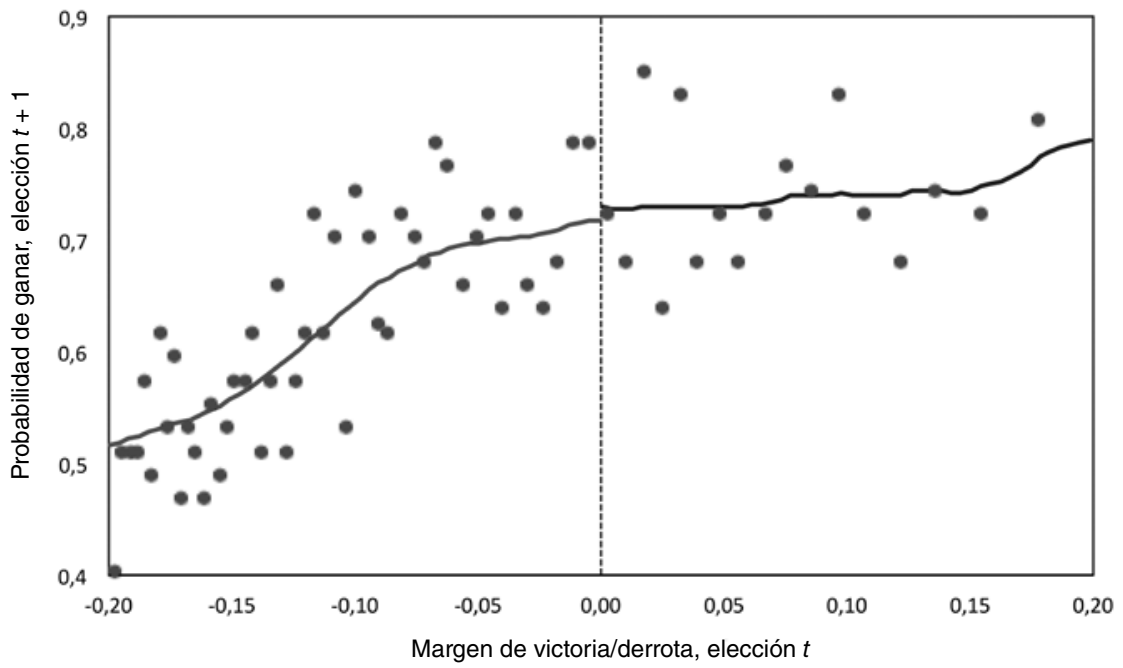




\section{CUADRO 4}

EFECTO INCUMBENTE A NIVEL DE PARTIDO, 1999-2011

\begin{tabular}{|c|c|c|c|c|c|c|}
\hline & \multicolumn{5}{|c|}{ RD Polinomial } & \multirow{2}{*}{$\begin{array}{c}\mathrm{RD} \\
\text { No } \\
\text { paramétrico }\end{array}$} \\
\hline & Lineal & Cuadrático & Cúbico & Cuártico & Quíntico & \\
\hline & $(1)$ & (2) & (3) & (4) & $(5)$ & $(6)$ \\
\hline \multicolumn{7}{|c|}{ Panel A: Probabilidad de ganar elección en $t+1$} \\
\hline Incumbente en $t$ & $\begin{array}{c}-0,0555^{* *} \\
(0,0234)\end{array}$ & $\begin{array}{c}-0,127 * * * \\
(0,0316)\end{array}$ & $\begin{array}{c}-0,0975 * * \\
(0,0402)\end{array}$ & $\begin{array}{l}-0,0667 \\
(0,0492)\end{array}$ & $\begin{array}{l}-0,0503 \\
(0,0589)\end{array}$ & $\begin{array}{c}-0,0814 * * \\
(0,0359)\end{array}$ \\
\hline Observaciones & 7.055 & 7.055 & 7.055 & 7.055 & 7.055 & 7.055 \\
\hline R-cuadrado & 0,080 & 0,085 & 0,087 & 0,088 & 0,088 & \\
\hline \multicolumn{7}{|c|}{ Panel B: Probabilidad de participar en elección $t+1$} \\
\hline Incumbente en $t$ & $\begin{array}{c}0,0384 \\
(0,0275)\end{array}$ & $\begin{array}{c}-0,0709 * * \\
(0,0354)\end{array}$ & $\begin{array}{l}-0,0528 \\
(0,0437)\end{array}$ & $\begin{array}{l}-0,0564 \\
(0,0522)\end{array}$ & $\begin{array}{c}-0,00547 \\
(0,0605)\end{array}$ & $\begin{array}{l}-0,0433 \\
(0,0348)\end{array}$ \\
\hline Observaciones & 7.055 & 7.055 & 7.055 & 7.055 & 7.055 & 7.055 \\
\hline R-cuadrado & 0,104 & 0,108 & 0,109 & 0,109 & 0,109 & \\
\hline \multicolumn{7}{|c|}{ Panel C: Probabilidad de mantener candidato en elección $t+1$} \\
\hline Incumbente en $t$ & $\begin{array}{c}0,109 * * * \\
(0,0251)\end{array}$ & $\begin{array}{c}0,0306 \\
(0,0335)\end{array}$ & $\begin{array}{c}0,0153 \\
(0,0428)\end{array}$ & $\begin{array}{c}0,0339 \\
(0,0331)\end{array}$ & $\begin{array}{c}-0,00772 \\
(0,0614)\end{array}$ & $\begin{array}{c}0,0220 \\
(0,0370)\end{array}$ \\
\hline Observaciones & 7.055 & 7.055 & 7.055 & 7.055 & 7.055 & 7.055 \\
\hline R-cuadrado & 0,139 & 0,145 & 0,146 & 0,146 & 0,146 & \\
\hline
\end{tabular}

Todas las regresiones incluyen efectos fijos por municipio. Errores estándar robustos (en paréntesis) se calculan a base de clusters al nivel de municipio-elección.

$* * * \mathrm{p}<0,01 ; * * \mathrm{p}<0,05 ; * \mathrm{p}<0,1$.

Por su parte, la Figura $5 \mathrm{~b}$ muestra la probabilidad de que el partido decida participar en la elección $t+1$ nuevamente en función de su margen de victoria/derrota en la elección $t$. En este caso encontramos que en el punto de corte no existen diferencias sistemáticas entre partidos incumbentes y no incumbentes, por lo que este no parece ser un factor decisivo en la decisión de participar en elecciones.

En el Cuadro 4 se muestran las estimaciones del efecto incumbente para los partidos políticos para tres distintas variables de interés: (i) La probabilidad (incondicional) de ganar la elección en $t+1$, (ii) la probabilidad de participar en la siguiente elección y (iii) la probabilidad (incondicional) de postular al mismo candidato de la elección $t$ en la elección en $t+1$.

Igual que para el Cuadro 3, se realizó un ejercicio de calibración de los resultados de las estimaciones no paramétricas utilizando distintos anchos de banda, los que se presentan de forma gráfica en la Figura 6. 
FIGURA 6

ESTIMACIONES NO PARAMETRICAS UTILIZANDO DISTINTOS ANCHOS DE BANDA EN UNA VENTANA EN TORNO AL ANCHO DE BANDA OPTIMO

(a)

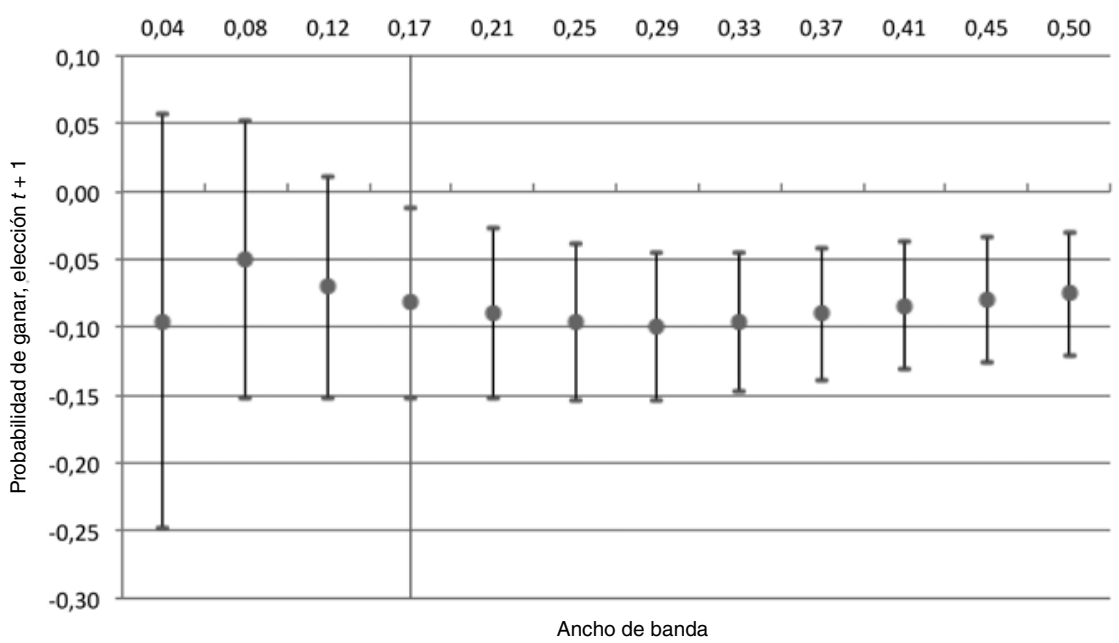

(b)

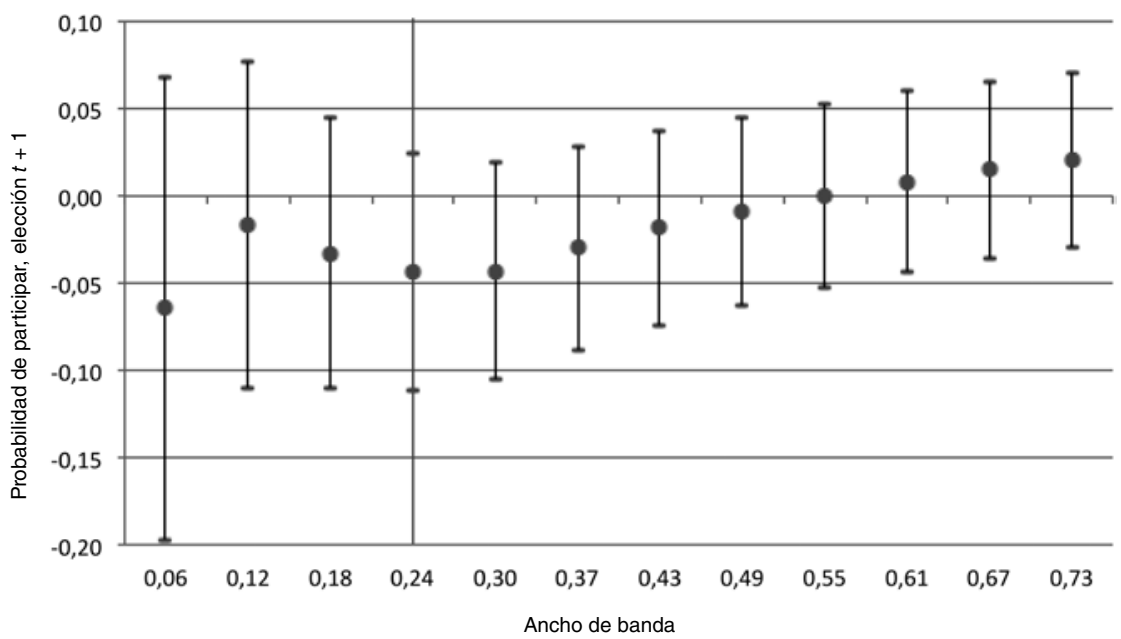


(c)

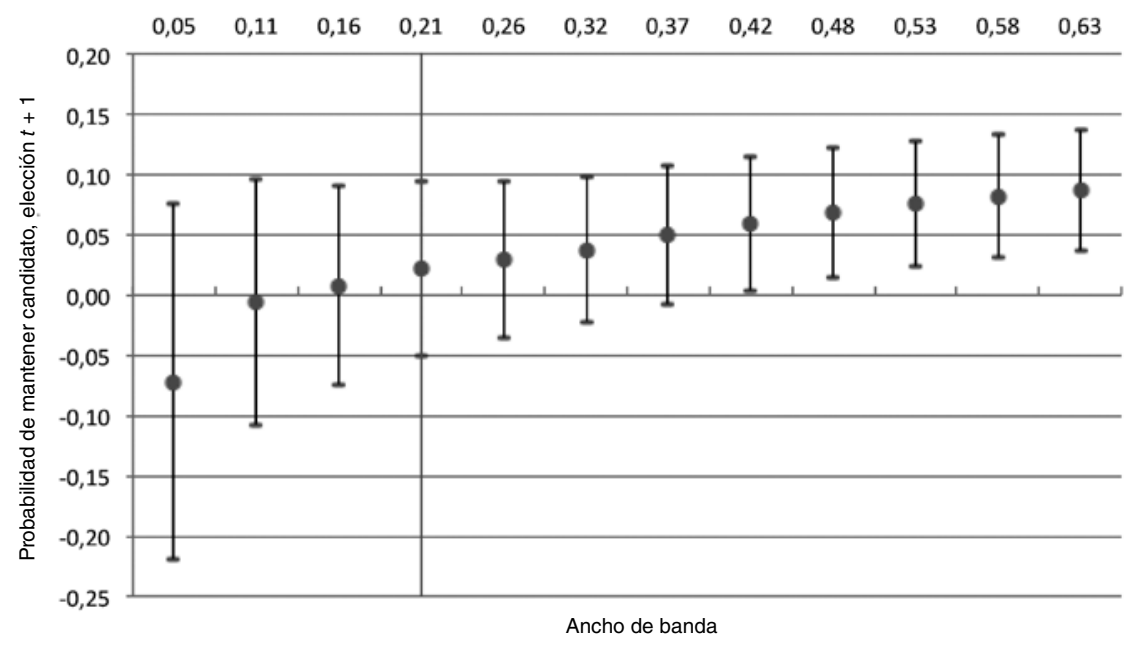

Nota: Las líneas negras representan el intervalo de confianza de los estimadores y la línea gris el estimador óptimo de Imbens y Kalyanaraman (2012).

En el Panel $A$ encontramos que la probabilidad de que el partido incumbente sea reelegido es negativa y significativa ${ }^{5}$, con un efecto negativo en torno al $8 \%$. Ello implicaría que existe un traspaso parcial del efecto del performance del incumbente a la marca partidaria y que el voto de castigo también sigue una lógica partidaria.

Sin embargo el resultado no es tan grande en magnitud, ni robusto a distintas especificaciones del polinomio, lo que nos indica que no es tan importante como el encontrado para el caso individual. Esta ambigüedad en los resultados también está presente en las regresiones no paramétricas, como se observa en la Figura 6a.

En cuanto a la probabilidad de participar en la siguiente elección, en el Panel B, los resultados no son significativos, con esto la incumbencia a nivel de partidos no parece estar afectando sus decisiones de participación. Ello es consistente con la estrategia de los partidos de mantener una presencia constante en elecciones municipales a nivel nacional, independientemente de que hayan ganado o perdido, para cumplir con los requisitos mínimos de organización partidaria que exige la Ley Electoral y de Partidos Políticos (ASIES, 2008).

Finalmente, en el Panel $C$ y la Figura 6c se muestra el efecto de la incumbencia sobre la probabilidad incondicional de que el partido postule al mismo candidato durante la siguiente elección. Encontramos que no existe ningún efecto significativo

5 Estimación preferida por criterio de información de Akaike: regresión con polinomio de grado 3. 
de la incumbencia. Ello contrasta con el efecto significativo del transfuguismo encontrado a nivel individual.

\subsection{Discusión sobre los resultados: posibles causas}

De los resultados de las estimaciones empíricas se ha encontrado que existe un efecto incumbente negativo y significativo tanto para candidatos individuales como para partidos políticos que participan en elecciones municipales. Este resultado $a$ priori contrasta con las posibles ventajas que podría presentar la incumbencia para un individuo de acuerdo con la literatura teórica. Sin embargo en años recientes ha surgido una creciente literatura empírica interesada en estimar este efecto para distintos países en desarrollo y los resultados encontrados son directamente comparables y consistentes con los de este trabajo.

Un importante trabajo es el de Titiunik (2009), quien estima el efecto incumbente a nivel de partidos para elecciones municipales en Brasil. La magnitud de los efectos encontrada es similar a la del presente trabajo. La autora encuentra efectos negativos en torno al $20 \%$ en la probabilidad de ser reelegido para los alcaldes de los tres principales partidos a nivel nacional. Debido a que esta es una estimación a nivel de partidos, la comparación con el efecto incumbente individual encontrado para Guatemala no es directa.

Por su parte Miguel y Zaidi (2003), utilizando datos para elecciones parlamentarias nacionales en Ghana, encuentran un efecto incumbente negativo pero no significativo en la probabilidad de ser reelegido.

Linden (2004), estudiando las elecciones parlamentarias en India a nivel nacional, obtiene un resultado similar al encontrado en este trabajo, mostrando los incumbentes $14 \%$ menos de probabilidad de ser elegidos. Finalmente, Uppal (2009) hace una estimación similar para las elecciones parlamentarias estatales en India, encontrando efectos negativos en torno al $15-20 \%$.

Si bien estos resultados son similares a los encontrados para Guatemala, contrastan de forma considerable con los encontrados por la amplia literatura empírica para democracias más estables. La gran mayoría de evidencia encontrada es para las elecciones al Congreso estadounidense (ver Erikson, 1971; Ferejohn, 1977; Jacobson, 1987; Ansolabehere, Brady y Fiorina, 1992; Gelman y King, 1990; Cox y Morgenstern, 1993; Cox y Katz, 1996; Levitt y Wolfram, 1997; Ansolabehere, Snyder y Stewart, 2000). Esta literatura se enfoca principalmente en la estimación de la ventaja individual de los miembros del Congreso, sin embargo también se ha demostrado que esta ventaja se extiende a los partidos políticos (Lee, 2008).

La literatura empírica ofrece poco en términos de explicaciones teóricas para explicar la existencia de un efecto incumbente negativo. Por el momento solo se han ofrecido algunas especulaciones informales sobre las causas potenciales, tales como la existencia de partidos débiles (Titiunik, 2009; Brambor y Ceneviva, 2011), insuficiente provisión de bienes públicos (Uppal, 2009), o un cambio estructural en el sistema de partidos políticos (Linden, 2004). Los trabajos, sin embargo, no testean el efecto causal de estos factores, ni ofrecen una teoría sobre el mecanismo de influencia. 
La literatura teórica sobre accountability, por su parte, ha sido elaborada principalmente tomando como base el entorno institucional de una democracia consolidada. Por lo que a causa de la amplia evidencia empírica existente, se ha concentrado principalmente en explicar teóricamente las ventajas de la incumbencia.

En los primeros modelos de agencia con riesgo moral (Barro, 1973; Ferejohn, 1986; Austen-Smith y Banks, 1989; Banks y Sundaram, 1993) se parte del supuesto de que todos los políticos son iguales. Esto permite que el votante se comprometa a una regla de reelección. En equilibrio, estas reglas disciplinan al incumbente de tal manera que el elector es indiferente entre mantenerlo en el poder o sustituirlo. Si bien esto implica una tasa de retención arbitraria, es posible alcanzar equilibrios con altas tasas de retención.

Por otro lado, en los modelos que incorporan selección adversa, los políticos difieren únicamente en su tipo (o calidad) y pueden emitir señales a los votantes sobre su habilidad en la implementación de políticas (Rogoff, 1990). En este tipo de modelos con selección adversa pura, las elecciones sólo sirven como mecanismo para seleccionar el tipo de candidato que servirá de mejor manera a los intereses de los votantes (Fearon, 1999).

Otro tipo de modelos combinan el riesgo moral y la selección adversa, por lo que existe una interacción entre el rol disciplinario y el rol de selección de las elecciones (Banks y Sundaram, 1998; Besley y Smart, 2007). La incertidumbre sobre el tipo del incumbente implica que el votante no puede comprometerse a una regla de reelección que solo tome en cuenta el desempeño político. Como consecuencia de ello, surge a partir del modelo una ventaja de ser incumbente, debido a la asimetría en las oportunidades entre los incumbentes y otros candidatos para señalar su tipo a los votantes (Besley, 2006).

En un trabajo relacionado, Svolik (2013) modela un país recientemente democratizado en el que los políticos aún deben establecer reputaciones. Algunos candidatos son intrínsecamente malos, en el sentido de que la amenaza de no reelección no les detiene de buscar rentas. Otros son normales en el sentido de que pueden ser disciplinados mediante elecciones.

El desempeño en el cargo es una señal informativa imperfecta del tipo del candidato. Sin embargo al votante le resulta costoso monitorear el comportamiento de los políticos, y puede optar por ignorar el rendimiento del incumbente y simplemente elegir a otro candidato de la lista de candidatos potenciales.

Bajo este escenario es posible llegar a un equilibrio de expectativas pesimistas y antiincumbencia. La decepción repetida hace que los electores eventualmente no hagan caso al rendimiento del incumbente. Esto induce un efecto incumbente negativo y, ya que el rendimiento es ignorado, todos los políticos incurren abiertamente en búsqueda de rentas.

Myerson (2006) desarrolla un modelo con un resultado similar, antes de examinar los mecanismos mediante los cuales la competencia entre los candidatos puede ayudar a evitar esta falta de rendición de cuentas. Si bien estos modelos proporcionan un fundamento temporal para la antiincumbencia, sus resultados no son consistentes con otros hechos estilizados de las democracias en países en desarrollo. 
De acuerdo con Klasnja (2011), hay al menos dos razones distintas acerca de por qué la búsqueda de rentas puede ser más alta en una democracia joven que en una desarrollada. En primer lugar, hubo poco tiempo para que los políticos, así como los partidos políticos, puedan establecer reputaciones. Por lo tanto, las barreras de entrada a los políticos de diferentes niveles de calidad son bajas. Luego los mayores niveles de búsqueda de rentas pueden ser una consecuencia de la capacidad de políticos de mala calidad de postularse y ganar elecciones.

En segundo lugar, las democracias menos desarrolladas tienen instituciones más débiles que son menos eficaces en limitar el comportamiento oportunista de los políticos. Esta debilidad institucional también puede producir un mayor nivel de captación de rentas: es decir, un político corrupto será capaz de extraer más rentas. Pero lo más importante es que esta debilidad puede dar margen para un aumento de la oportunidad de búsqueda de rentas durante el período del político en el poder.

Basado en ello, el autor propone un modelo que transcurre en un entorno institucional débil en el que un político buscador de rentas puede ser capaz de extraer rentas crecientes en el tiempo. Con ello se generan los incentivos para la existencia de un efecto incumbente negativo, ya que es la única forma en que los votantes pueden limitar la cantidad de rentas extraídas por los políticos en el poder.

Este argumento es interesante, y podría brindar una racionalidad a los resultados empíricos encontrados en el trabajo. A continuación se propone una forma indirecta para testear empíricamente esta hipótesis con datos para Guatemala, utilizando el diseño de las elecciones municipales y la conformación del Concejo Municipal.

\section{RENT-SEEKING: POSIBLE EXPLICACION PARA UN EFECTO INCUMBENTE NEGATIVO}

De acuerdo con la hipótesis planteada en la sección anterior, el efecto incumbente negativo surgiría de un intento de los votantes por limitar la búsqueda de rentas de los políticos en el poder. A causa de la debilidad institucional para restringir la actuación del alcalde en el poder, el voto de castigo es la única herramienta con la que se cuenta para limitar su actuación. Aun cuando el alcalde no responda a la amenaza de los votantes (es decir, es de mala calidad), es preferible limitar su estadía en el poder a un período, que permitir que permanezca y crezca el nivel de rentas que puede extraer.

Sin embargo, la capacidad que tiene el político para extraer rentas es variable y puede ser limitada por la existencia de un Concejo Municipal dividido. En virtud de que por definición en nuestro análisis nos enfocamos principalmente en elecciones competitivas en las que el margen de victoria del alcalde es muy pequeño, por la forma en que están diseñadas las elecciones municipales, existe una alta probabilidad que tenga que enfrentarse a un Concejo dividido, ello puede ser un freno a su actuación en el poder.

Como se mencionó anteriormente, en las elecciones municipales los votantes eligen entre distintos partidos políticos, estos postulan cada uno un listado que incluye al alcalde, síndicos y concejales. El alcalde y los síndicos son adjudicados al partido ganador por mayoría simple, mientras que los concejales se reparten mediante un 
sistema de representación proporcional (fórmula D’hondt). El Concejo Municipal es quien por ley gobierna el municipio, y delega sus funciones de ejecución en el alcalde, quien debe rendir cuentas ante este.

Mack (2006) reconoce que la existencia de un Concejo dividido en elecciones locales es un aspecto que ha sido poco explorado por la literatura. En virtud de la alta competitividad de las elecciones locales, este es un fenómeno que tiende a prevalecer en gran medida. Ello es particularmente cierto en el caso de nuestro trabajo, el que por definición se enfoca en elecciones en las cuales el margen de ganancia es muy cerrado.

De igual manera Torres-Rivas y Cuesta (2007) reconocen que la fórmula de asignación proporcional del Concejo Municipal permite mejorar la representatividad y hacer un contrapeso de poderes e intereses, sin embargo también puede conducir a situaciones de enfrentamientos y conflictos entre el alcalde y sus integrantes. En ese sentido es interesante explorar hasta qué punto la conformación del Concejo puede estar afectando la capacidad del alcalde de gobernar.

En este caso, si la evidencia empírica es consistente con la hipótesis planteada, debiésemos encontrar que en municipios donde el alcalde cuenta con mayoría en el Concejo, este no contará con una oposición efectiva que limite la cantidad de rentas que puede extraer de su posición política y por lo tanto el efecto incumbente debiese ser más negativo, es decir, su probabilidad de ser reelegido debiese disminuir.

Por otro lado, si el alcalde se enfrenta a un Concejo dividido se verá más limitado en su capacidad de buscar rentas, y por lo tanto se esperaría que los votantes reconocieran esa situación (o lo confundiesen con un alcalde con calidad) y por ende se probabilidad de ser reelegido debiese aumentar.

Empíricamente, la conformación del Concejo y su interacción con el alcalde puede explotarse de dos formas: (i) mediante el uso de coaliciones a nivel nacional, que se reflejen a nivel local o (ii) explotando la diferencia en el tamaño del Concejo (en función del tamaño de la población del municipio) y por ende en la dificultad que el alcalde enfrente al negociar con un Concejo dividido. A continuación se exploran cada una de estas alternativas.

\subsection{Efecto de las coaliciones}

Debido a la alta volatilidad del sistema de partidos políticos en Guatemala es difícil hablar sobre coaliciones estables entre partidos políticos. Sin embargo, por la alta fragmentación del Congreso, estas se vuelven necesarias como parte del proceso de negociación para que el partido en el poder ejecutivo pueda gobernar y proponer legislaciones de interés. Este fenómeno ha sido particularmente importante a partir de la elección del 2003, en la que ningún partido político obtuvo mayoría en el Congreso.

En muchos casos estas alianzas son tácitas, es decir, no se formalizan de forma legal, sino que solo están dadas por el interés mutuo de partidos en promover la aprobación de ciertas leyes, sin embargo en algunos casos estas alianzas se formalizan en una coalición electoral para el período electoral siguiente.

En ese sentido, una manera de abordar el efecto del Concejo Municipal sobre la capacidad de gobernar del alcalde viene dada por trasladar las coaliciones partidarias 
que se formaron a nivel nacional al ámbito del gobierno local. Luego se evalúan las municipalidades en las que un alcalde de turno ganó la elección contra un partido que forma parte de la coalición a nivel nacional, en comparación a otras, para detectar si existe un efecto incumbente diferenciado por el hecho de contar con mayoría en el Concejo (vía coalición).

\subsubsection{0-2003: FRG}

En la elección de 1999 el partido Frente Republicano Guatemalteco (FRG) ganó la elección presidencial y obtuvo una mayoría en el Congreso con aproximadamente $56 \%$ de los escaños (Lehoucq, 2002). Este conservó la mayoría absoluta a lo largo de todo el período, por lo que no necesitó establecer formalmente ninguna alianza para poder impulsar su agenda. Aun así, generalmente contó con la adhesión a la hora de las votaciones de los partidos de la DCG y el del PLP (ASIES, 2008).

Estableciendo este apoyo a nivel del Congreso como una alianza tácita entre partidos, encontramos que solo en $4 \%$ de las municipalidades el primer y segundo lugar perteneció a partidos de la coalición. Por lo que, en términos de lograr una identificación del Concejo, esta alianza es poco relevante.

\subsubsection{4-2007: GANA}

En las elecciones de 2003 la Gran Alianza Nacional (GANA), una coalición electoral conformada por tres partidos (PP, MR y PSN), ganó la elección presidencial. Sin embargo, a diferencia de elecciones anteriores, esta no obtuvo una mayoría en el Congreso, sino que el voto se dividió entre cuatro grandes bloques: GANA (30\%), FRG (27\%), UNE (20\%) y el PAN (10\%) (Azpuru, 2005). Ello obligó al partido del presidente a negociar el denominado "Pacto de Gobernabilidad" entre la GANA, el PAN y la UNE, esto se vio reflejado en la conformación de la Junta Directiva del Congreso.

Tomando como referencia este pacto, se puede establecer que $15 \%$ de las elecciones municipales el primer y segundo lugar fue disputado entre partidos pertenecientes a la alianza suscrita entre partidos a nivel nacional.

\subsubsection{8-2011: UNE}

La elección del 2007 tuvo como resultado el triunfo en elecciones presidenciales de la Unidad Nacional de la Esperanza (UNE). Igual que en el período de gobierno anterior, ningún partido obtuvo mayoría en el Congreso. En este caso se conformaron cuatro bloques principales: UNE (32\%), GANA (23\%), PP (18\%) y el FRG (8\%) (Azpuru, 2008). Sin embargo en este caso se logró establecer una importante y estable alianza entre la UNE y el partido GANA (ASIES, 2010), la que posteriormente se tradujo en una coalición electoral para las elecciones del 2011.

En este caso se tiene evidencia de una coalición más estable, ello también tuvo importante presencia a nivel local. De acuerdo con la muestra, en $25 \%$ de las elecciones municipales el primer y segundo lugar fue disputado por partidos miembros de 
esta coalición, por lo que los alcaldes gobernando en esta debiesen contar con menor oposición por parte del Concejo para gobernar.

\subsubsection{Estimaciones}

A partir de las coaliciones descritas anteriormente se construye una variable que toma en cuenta únicamente a las municipalidades en las que el primer y segundo lugar fue disputado entre partidos miembros de la coalición o alianza. Esta variable luego es interactuada por la variable de incumbencia para encontrar si existe un efecto diferenciado en la probabilidad de ganar en la elección $t+1$.

Se espera a priori que el signo de la interacción sea negativo, reflejando el hecho que cuando el alcalde cuenta con un partido de coalición en el Concejo, cuenta con menores restricciones para actuar, y por ende puede extraer rentas con mayor facilidad. Los votantes reconocerían esta situación y en la próxima elección utilizarían el voto de castigo contra el alcalde incumbente. Los resultados se presentan en el Cuadro 5.

La estimación se realizó para toda la muestra (con y sin efectos fijos por municipio), y posteriormente de manera separada para cada período. Como se puede observar, en todos los casos (excepto en (3)) el efecto incumbente es negativo y significativo, indicando que la penalidad contra el incumbente existe en consejos muy competitivos.

\section{CUADRO 5}

EFECTO INCUMBENTE (INCLUYENDO EFECTO COALICION) EN LA PROBABILIDAD DE GANAR EN ELECCION $t+1$

\begin{tabular}{|lccccc|}
\hline & $(1)$ & $(2)$ & $(3)$ & $(4)$ & $(5)$ \\
\hline Incumbente en $t$ & $-0,119 * * *$ & $-0,116^{* * *}$ & $-0,149$ & $-0,153^{*}$ & $-0,309 * *$ \\
& $(0,0461)$ & $(0,0445)$ & $(0,112)$ & $(0,0921)$ & $(0,136)$ \\
Coalición*incumbente & $-0,0250$ & $-0,0244$ & & & \\
& $(0,0682)$ & $(0,0662)$ & & & \\
Coalición*incumbente (2000-2003) & & & $-0,986^{* *}$ & & \\
& & & $(0,498)$ & & \\
Coalición*incumbente (2004-2007) & & & & 0,208 & \\
& & & & $(0,172)$ & \\
Coalición*incumbente (2008-2011) & & & & & $-0,138$ \\
& & & & & \\
Constante & $0,430 * * *$ & $0,324 * * *$ & $0,394 * * *$ & $0,549 * * *$ & $0,583 * * *$ \\
& $(0,0217)$ & $(0,0212)$ & $(0,0535)$ & $(0,0432)$ & $(0,0687)$ \\
Grado del polinomio & 3 & 3 & 4 & 3 & 5 \\
Grado de la interacción & 2 & 2 & 5 & 3 & 5 \\
Efectos fijos & $\mathrm{Si}$ & $\mathrm{No}$ & $\mathrm{Si}$ & $\mathrm{Si}$ & $\mathrm{Si}$ \\
Observaciones & 7.049 & 7.049 & 1.900 & 2.584 & 2.565 \\
R-cuadrado & 0,207 & 0,171 & 0,301 & 0,268 & 0,261 \\
\hline
\end{tabular}

Nota: Todas las regresiones se estiman de forma paramétrica. Se presenta la estimación con el grado de polinomio preferido basado en el criterio de información de Akaike.

Errores estándar robustos (en paréntesis) se calculan a base de clusters al nivel de municipio-elección. $* * * \mathrm{p}<0,01 ; * * \mathrm{p}<0,05 ; * \mathrm{p}<0,1$. 
En el caso de las regresiones con la muestra completa, la inclusión o exclusión de efectos fijos no genera ninguna variación en el resultado.

En general los coeficientes asociados al efecto coalición son los esperados (negativos), sin embargo no son estadísticamente significativos. Ello nos indica que parte de la variación puede estar siendo explicada por la hipótesis propuesta, sin embargo otros factores parecen influir también.

Particularmente llama la atención el efecto encontrado para la regresión (3), que toma en cuenta únicamente el período de gobierno del 2000 al 2003. En esta el coeficiente del efecto coalición es significativo, sin embargo su magnitud es demasiado grande y el efecto de la incumbencia pierde significancia.

Como se mencionó en el apartado anterior, durante este período el partido del presidente contó con mayoría en el Congreso, por lo que no necesitó establecer ninguna alianza partidaria. Adicionalmente, las municipalidades en donde se estima el efecto coalición son una parte muy pequeña de la muestra total, por ello los resultados pueden verse afectados.

También llama la atención la regresión (4), estimada para el período 2004-2007, en la que el efecto coalición es positivo (pero no significativo), contrario a la hipótesis inicial. De nuevo el resultado puede estar siendo afectado por la inestabilidad de la alianza, porque lo que sucedió a nivel nacional puede no ser representativo de la dinámica política a nivel local.

En general se reconoce la imperfección de usar una medida de coalición para estimar el efecto de tener una mayoría en el Concejo, por la alta volatilidad del sistema de partidos políticos que en general no asegura la solidez de las alianzas o coaliciones y tampoco garantiza que lo que ocurre a nivel nacional es un reflejo de lo que ocurre en la política local.

A continuación se propone una manera alternativa de estimar el efecto de contar o no con una mayoría en el Concejo Municipal.

\subsection{Efecto del tamaño del Concejo Municipal}

Anteriormente se definió que el tamaño del Concejo Municipal varía en función del tamaño de la población del municipio. De acuerdo con la Ley Electoral y de Partidos Políticos se establece la siguiente escala de integración de las corporaciones municipales en función del tamaño de la población del municipio:

- Tres síndicos y diez concejales titulares, en los municipios con más de cien mil habitantes.

- Dos síndicos y siete concejales titulares, en los municipios con más de cincuenta mil habitantes y menos de cien mil.

- Dos síndicos y cinco concejales titulares, en los municipios con más de veinte mil habitantes y hasta cincuenta mil.

- Dos síndicos y cuatro concejales titulares, en los municipios con veinte mil habitantes o menos. 
El Concejo Municipal es el ente rector del municipio y las decisiones se toman por mayoría simple. Tanto concejales como síndicos cuentan con derecho a un voto. En caso de empate a la hora de votar, el alcalde puede votar para aprobar o rechazar la iniciativa que está siendo votada.

Por diseño electoral, al asignarse por mayoría simple los puestos de síndicos al partido del alcalde, prácticamente se garantiza la conformación de mayorías en el Concejo. Aun así, según aumenta el tamaño del Concejo se vuelve más complejo para el alcalde obtener los votos necesarios para aprobar iniciativas, ya que debe negociar con un mayor número de personas. Luego se espera que en Concejos más grandes exista una mayor restricción a la actuación del alcalde, especialmente si este ganó la elección por un margen estrecho.

Esta idea se explota a continuación, para identificar empíricamente la hipótesis planteada anteriormente. Particularmente se espera que según aumenta el tamaño del Concejo la capacidad de extracción de rentas se limita (sea porque existe una mayor oposición o porque las rentas deben ser compartidas entre más personas), por esto el efecto de incumbencia negativo debiese disminuir.

Para ello se crean variables de identificación para cada uno de los cuatro tamaños de Concejo Municipal estipulados en la ley. Se establecen cuatro categorías: municipalidades pequeñas ( $\leq 20.000$ hab.), medianas $(\leq 50.000 \mathrm{y}>20.000$ hab.), grandes ( $\leq 100.000$ y $>50.000$ hab.) y muy grandes ( $>100.000$ hab.). Estas variables son luego interactuadas con la variable de incumbencia para obtener el efecto del tamaño del Concejo sobre la probabilidad del alcalde de ganar en la siguiente elección.

En términos prácticos se espera a priori que el coeficiente que acompaña las victorias por margen estrecho en municipalidades pequeñas sea negativo, mientras que para municipalidades grandes, positivo. El Cuadro 6 muestra los resultados de las estimaciones.

Como se observa, en todos los casos el efecto incumbente es negativo y significativo, indicando que independientemente del tamaño del Concejo Municipal la penalización al incumbente persiste. Los signos de las regresiones son los esperados a priori, sin embargo los coeficientes no son significativos. En general, cuando el tamaño del Concejo municipal es pequeño, el efecto incumbente se amplifica (en sentido negativo), mientras que según crece, el coeficiente contrarresta el efecto incumbente en sentido positivo.

Este hallazgo parece indicar que efectivamente los votantes valoran que se restrinja la capacidad de actuación del alcalde, de acuerdo con nuestra hipótesis, porque ello limita la capacidad del alcalde de extraer rentas. Sin embargo el hecho de que los coeficientes no sean significativos también indica que parecen existir otros factores que influyen la decisión de los votantes.

En particular, como en los modelos discutidos anteriormente, parece existir una interacción entre riesgo moral y selección adversa. Es decir, las elecciones parecen cumplir un rol de rendición de cuentas, como se evidencia de los resultados de este trabajo, pero a la vez también cumple uno de descubrimiento del tipo (o calidad) del individuo, lo que puede estar afectando los resultados encontrados. 


\section{CUADRO 6}

EFECTO INCUMBENTE (INCLUYENDO EFECTO TAMAÑO CONCEJO MUNICIPAL) EN LA PROBABILIDAD DE GANAR EN ELECCION $t+1$

\begin{tabular}{|lccccc|}
\hline & $(1)$ & $(2)$ & $(3)$ & $(4)$ & $(5)$ \\
\hline Incumbente en $t$ & $-0,0925^{*}$ & $-0,102^{* *}$ & $-0,192^{* * *}$ & $-0,196^{* * *}$ & $-0,209^{* *}$ \\
Gana en pequeño & $(0,0523)$ & $(0,0504)$ & $(0,0646)$ & $(0,0626)$ & $(0,0828)$ \\
& $-0,0773$ & $-0,0488$ & & & \\
Gana en mediano & $(0,0667)$ & $(0,0633)$ & & & \\
& & & & & $-0,0202$ \\
Gana en grande & & & & & $(0,0976)$ \\
& & & & & 0,211 \\
Gana en muy grande & & & 0,0234 & 0,0337 & $0,170)$ \\
& & & $(0,238)$ & $(0,232)$ & $(0,244)$ \\
Constante & $0,426^{* * *}$ & $0,324 * * *$ & $0,466^{* * *}$ & $0,362^{* * *}$ & $0,462 * * *$ \\
& $(0,0218)$ & $(0,0212)$ & $(0,0348)$ & $(0,0339)$ & $(0,0347)$ \\
Grado del polinomio & 3 & 3 & 5 & 5 & 5 \\
Grado de la interacción & 3 & 3 & 5 & 5 & 5 \\
Efectos fijos & Si & No & Si & No & Si \\
Observaciones & 7.049 & 7.049 & 7.049 & 7.049 & 7.049 \\
R-cuadrado & 0,209 & 0,174 & 0,208 & 0,173 & 0,215 \\
\hline
\end{tabular}

Nota: Todas las regresiones se estiman de forma paramétrica. Se presenta la estimación con el grado de polinomio preferido basado en el criterio de información de Akaike.

Errores estándar robustos (en paréntesis) se calculan a base de clusters al nivel de municipio-elección. $* * * \mathrm{p}<0,01 ; * * \mathrm{p}<0,05 ; * \mathrm{p}<0,1$.

\section{CONCLUSIONES}

El presente trabajo, utilizando datos para elecciones municipales en Guatemala, encuentra la existencia de un importante efecto incumbente negativo tanto para candidatos individuales como para partidos políticos en la probabilidad de ser elegido en elecciones posteriores.

Se encontraron efectos adicionales significativos de la incumbencia individual sobre la probabilidad de participar y cambiar de partido político en elecciones subsiguientes. En ese sentido, los resultados encontrados constituyen un aporte importante para comprender la dinámica de la política a nivel local en Guatemala.

Los resultados contrastan con las posibles ventajas que podría presentar la incumbencia para un individuo de acuerdo con la literatura teórica, sin embargo estos son consistentes con lo encontrado por la literatura empírica para otros países en desarrollo.

Este trabajo avanza en una explicación potencial para la existencia de un efecto incumbente, basándose en la idea de que en un entorno institucional débil, las barreras de entrada de políticos de mala calidad a elecciones locales son muy bajas, y una vez en el poder es posible que estos puedan extraer rentas de forma creciente. Ante esta 
situación, el voto de castigo es la única herramienta con la que cuenta el votante para limitar la extracción de rentas por parte de políticos incumbentes.

Esta hipótesis se testea indirectamente explotando la existencia de Concejos Municipales divididos en elecciones municipales competitivas. En general los resultados encontrados son mixtos, pero apuntan a la existencia de un rol de las elecciones, tanto como mecanismo de rendición de cuentas así como de mecanismo de descubrimiento y selección de la calidad de los políticos en el poder.

Por lo tanto podemos decir que constituyen un resultado preliminar alentador y abren una posible línea de investigación empírica que permita comprender de mejor manera los incentivos que enfrentan los políticos y el rol de los votantes en disciplinar a incumbentes en elecciones municipales.

En particular se reconoce como necesario estudiar la interacción entre los alcaldes y otros actores políticos tanto a nivel local como regional y nacional. Si bien los efectos encontrados en este trabajo son econométricamente válidos e importantes para comprender la actuación de los políticos y los votantes, aún persisten dudas sobre los mecanismos mediante los que estos operan.

Específicamente se ha mencionado que los alcaldes juegan un importante rol para movilizar a los votantes en las elecciones presidenciales, y este mecanismo podría explicar la importancia de los alcaldes para los partidos políticos a nivel nacional, así como las posibles decisiones de los alcaldes de migrar de un partido a otro.

De igual manera, resulta interesante profundizar en la elaboración de modelos teóricos que se ajusten a las condiciones institucionales particulares de los países en desarrollo como Guatemala, y que permitan a su vez ofrecer potenciales explicaciones sobre los mecanismos de los efectos encontrados y generalizar algunos de sus resultados.

\section{REFERENCIAS}

ANSOLABEHERE, S., W. BRADY y M. FIORINA (1992). "The Vanishing Marginals and Electoral Responsiveness", British Journal of Political Science 22, pp. 21-38.

ANSOLABEHERE, S., J. SNYDER y C. STEWART (2000). "Old voters, new voters, and the personal vote: Using redistricting to measure the incumbency advantage", American Journal of Political Science 44 (1), pp. 17-34.

ASIES (2008). Guatemala: monografía de los partidos políticos 2004-2008, Asociación de Investigación y Estudios Sociales: Departamento de Investigaciones Sociopolíticas, Guatemala.

ASIES (2010). Monografía del Congreso de la República 2008-2012. Asociación de Investigación y Estudios Sociales: Departamento de Investigaciones Sociopolíticas, Guatemala.

AUSTEN-SMITH, D. y J. BANKS (1989). "Electoral Accountability and Incumbency", en P. Ordeshook, Models of Strategic Choice in Politics, University of Michigan Press, Ann Arbor, pp. 121-150.

AZPURU, D. (2005). "The general elections in Guatemala, November-December 2003", Electoral Studies 24 (1), pp. 143-149.

AZPURU, D. (2008). "The 2007 presidential and legislative elections in Guatemala", Electoral Studies 27 (3), pp. 562-566.

BANKS, J. y R. SUNDARAM (1993). "Adverse Selection and Moral Hazard in a Repeated Elections Model”, en W. Barnett, M. Hinich y N. Schofield, Political Economy: Institutions, Information, Competition, and Representation, Cambridge University Press, Nueva York, pp. 295-312.

BANKS, J. y R. SUNDARAM (1998). “Optimal Retention in Agency Problems”, Journal of Economic Theory 82 (2), pp. 293-323. 
BARRO, R. (1973). "The Control of Politicians: an Economic Model”, Public Choice 14 (1), pp. 19-42.

BESLEY, T. (2006). Principled Agents? The Political Economy of Good Government. Oxford University Press, Oxford.

BESLEY, T. y M. SMART (2007). "Fiscal Restraints and Voter Welfare", Journal of Public Economics 91 (3), pp. 755-773.

BRAMBOR, T. y R. CENEVIVA (2011). "Incumbency Advantage in Brazilian Mayoral Elections", APSA 2011 Annual Meeting Paper.

BROOCKMAN, D. (2009). "Do congressional candidates have reverse coattails? Evidence from a regression discontinuity design", Political Analysis 17 (4), pp. 418-434.

BUTLER, D. (2009). "A regression discontinuity design analysis of the incumbency advantage and tenure in the U.S. House", Electoral Studies 28 (1), pp. 123-128.

CAUGHEY, D. y J. SEKHON (2012). "Elections and the regression-discontinuity design: Lessons from U.S. house races, 1942-2008”, Political Analysis 19 (4), pp. 385-408.

COVER, A. (1977). "One good term deserves another: the advantage of incumbency in congressional elections", American Journal of Political Science 21 (3), pp. 523-541.

COX, G. y J. KATZ (1996). "Why Did the Incumbency Advantage in U.S. House Elections Grow?", American Journal of Political Science 40 (2), pp. 478-497.

COX, G. y S. MORGENSTERN (1993). "The Increasing Advantage of Incumbency in the U.S. States", Legislative Studies Quarterly 18 (4), pp. 495-514.

DOWNS, A. (1957). An Economic Theory of Democracy, Harper and Row, Nueva York.

ERIKSON, R. (1971). “The Advantage of Incumbency in Congressional Elections”, Polity 3 (3), pp. $395-405$.

FEARON, J. (1999). "Electoral Accountability and the Control of Politicians: Selecting Good Types versus Sanctioning Poor Performance", en A. Przeworski, C. Stokes y B. Manin, Democracy, Accountability and Representation, Cambridge University Press, Cambridge, pp. 55-97.

FEREJOHN, J. (1977). "On the Decline of Competition in Congressional Elections", American Political Science Review 71 (1), pp. 166-176.

FEREJOHN, J. (1986). "Incumbent Performance and Electoral Control”, Public Choice 50 (1), pp. 5-25.

FORTIN, J. (2010). "Transfuguismo Parlamentario en Guatemala: Un Caso de Altos Costos de Asociación, Monopolio Partidario y Bajos Costos de Transacción”, América Latina Hoy 54, pp. 141-166.

GELMAN, A. y G. KING (1990). "Estimating Incumbency Advantage Without Bias”, American Journal of Political Science 34 (4), pp. 1142-1164.

GOMEZ, J. y M. GEFFNER (2005). "Guatemala: Fortalecimiento de las Finanzas Municipales para el Combate a la Pobreza", en CEPAL, Seminario Regional "Financiamiento Municipal y Superación de la Pobreza Urbana", CEPAL, Santiago de Chile.

IMBENS, G. y K. KALYANARAMAN (2012). "Optimal Bandwidth Choice for the Regression Discontinuity Estimator”, Review of Economic Studies 79 (3), pp. 933-959.

JACOBSON, G. (1987). "The Marginals Never Vanished: Incumbency and Competition in Elections to the U.S. House of Representatives, 1952-1982”, American Journal of Political Science 31 (1), pp. 126-141.

KLASNJA, M. (2011). "Increasing Rents and Incumbency Disadvantage". NYU Working Paper, Wilf Family Department of Politics, New York University.

LEE, D. (2008). "Randomized experiments from non-random selection in U.S. House elections", Journal of Econometrics 142 (2), pp. 675-697.

LEE, D. y T. LEMIEUX (2010). "Regression discontinuity designs in economics", Journal of Economic Literature 48 (2), pp. 281-355.

LEHOUCQ, F. (2002). “The 1999 elections in Guatemala”, Electoral Studies 21(1), pp. 101-154.

LINDEN, L. (2004). "Could Have Been a Contender? The Effects of Limiting the Number of Candidates in Indian State Parliamentary Elections", Columbia University Working Paper.

LEVITT, S. y C. WOLFRAM (1997). "Decomposing the sources of incumbency advantage in the U.S. House", Legislative Studies Quarterly 22 (1), pp. 45-60.

McCRARY, J. (2008). "Manipulation of the Running Variable in the Regression Discontinuity Design: A Density Test”, Journal of Econometrics 142 (2), pp. 698-714.

MACK, L. (2006). 20 años de procesos electorales municipales en Guatemala. FLACSO: Cuadernos de Información Política $N^{\circ} 3$, Guatemala.

MACK, L. y W. SONNLEITNER (2006). "El mosaico guatemalteco (1): Tendencias territoriales del voto y pulverización partidista en una sociedad altamente fragmentada”, en W. Sonnleitner, Explorando los 
territorios del voto: Hacia un Atlas electoral de Centroamérica, CEMCA-BID-IHEAL, Guatemala, pp. 67-73.

MAINWARING, S. y M. TORCAL (2006). "Party System Institutionalization and Party System Theory After the Third Wave of Democratization", en R. Katz y W. Crotty, Handbook of Political Parties, Sage, Londres, pp. 204-227.

McCONNELL, S., E. STUART y B. DEVANEY (2008). "The Truncation-by-Death Problem: What to Do in an Experimental Evaluation When the Outcome is Not Always Defined", Evaluation Review 32 (2), pp. 157-186.

MIGUEL, E. y F. ZAIDI (2003). "Do politicians reward their supporters? Regression discontinuity evidence from Ghana". Working Paper, Department of Economics, University of California.

MYERSON, R. (2006). "Federalism and Incentives for Success of Democracy", Quarterly Journal of Political Science 1, pp. 3-23.

PORTER, J. (2003). "Estimation in the Regression Discontinuity Model". Harvard University manuscript, Department of Economics.

ROGOFF, K. (1990). "Equilibrium Political Budget Cycles", American Economic Review 80 (1), pp. 21-37.

SANCHEZ, O. (2008). "Guatemala's Party Universe: A Case Study in Underinstitutionalization". Latin American Politics and Society 50 (1), pp. 123-151.

SVOLIK, M. (2013). "Learning to Love Democracy: Electoral Accountability and the Success of Democracy", American Journal of Political Science 57 (3), pp. 685-702.

TITIUNIK, R. (2009). "Incumbency advantage in Brazil: Evidence from municipal mayor elections". $\mathrm{Ph} . \mathrm{D}$. Thesis, University of California, Berkeley.

TORRES-RIVAS, E. y P. CUESTA (2007). Notas sobre la democracia y el poder local, Programa de las Naciones Unidas para el Desarrollo, Guatemala.

TROUNSTINE, J. (2011). "Evidence of a local incumbency advantage", Legislative Studies Quarterly 36 (2), pp. 225-280.

UPPAL, Y. (2009). "The Disadvantaged Incumbents: Estimating Incumbency Effects in Indian State Legislatures", Public Choice 138 (1), pp. 9-27.

VILLAMIZAR, F. (2007). "El Transfuguismo Político en Guatemala: ¿Un mal sin remedio o un inicio para la conformación de partidos políticos?", Revista Electrónica del EPRI (REPRI) 3 (11), pp. 7-15. 